\title{
THE PIVOT: HOW FOUNDERS RESPOND TO FEEDBACK THROUGH IDEA AND IDENTITY WORK
}

\author{
MATTHEW G. GRIMES \\ University of Cambridge
}

\begin{abstract}
Efforts to incorporate external feedback are central to the process of entrepreneurship and to that of creative work more broadly, yet, because individuals may view aspects of their creative ideas as linked to their self-concepts, this can trigger resistance toward revision. Thus, feedback-induced change, while likely intended to increase the viability of creative ideas, might paradoxically undermine that viability by compromising creative workers' associated identity-based relationships with their creative endeavors. While existing scholarship has established the importance of creative revision, research has largely overlooked how this vital process intersects with creative workers' identities. Through a field study of 59 founders and their entrepreneurial ideas, I present an identity-based process model of creative revision that highlights differences in founders' psychological ownership of their ideas and how those differences affect subsequent revision efforts. The emerging findings contribute to existing theory by revealing that the capacity to extend the novelty and usefulness of one's ideas is not merely subject to informational constraints but also to identity-based constraints.
\end{abstract}

Every founder has to be determined and stubborn ... But a great founder-she also realizes that she can be that stubborn and determined but also adaptive and flexible.

-Alexis Ohanian, Partner at Y Combinator

(Ferriss, 2015)

I started this company because the idea spoke to me. It's about who I am as a person and how I see the world. ... But this is also why this whole process of shopping my idea around to investors is difficult, because, when I open up my idea to criticism, I'm also exposing myself, if that makes sense. I'm just not sure how much I'm willing to change about my idea, because that would mean changing an important part of me.

-Founder of a 1-month-old health care start-up

Recently, scholars have begun to establish the significance of the creative revision process, whereby feedback providers and recipients engage in

I would like to extend my sincere gratitude to associate editor Elaine Hollensbe and the three anonymous reviewers who generously guided my own idea work and creative revision. I also wish to acknowledge the important and constructive feedback I received on early versions of this manuscript from Greg Fisher, Joel Gehman, Dev Jennings, Michael Lounsbury, Elizabeth Long Lingo, Jeff McMullen, Tim Pollock, Mike Pratt, Ranga Ramanujam, Elizabeth Rouse, Roy Suddaby, Marc Ventresca, Bart Victor, and Timothy Vogus, as well as the hosts and participants at the 2015 University of California, Davis, Qualitative Research Conference. efforts to improve the novelty and usefulness of an idea (Harrison \& Rouse, 2015; Perry-Smith \& Mannucci, 2015). This research on creative revision is important because it reveals a process that is interactive and evolving, in which the viability of creative work involves exposing one's ideas or prototypes to and responding to feedback from potential stakeholders (e.g., resource providers). Such a perspective on creative revision is perhaps most clearly relevant in contexts such as the early stages of innovation and entrepreneurship, wherein individuals attempt to commercialize their ideas, necessitating interactions with potential stakeholders to improve the alignment between their proposed ideas and the markets or audiences they are attempting to reach and influence (Bammens \& Collewaert, 2014; Lounsbury \& Glynn, 2001).

This recent work on the interactive process of creative revision opens up opportunities for research on the dynamic and complex reality of how creative workers respond to feedback. One such opportunity relates to how feedback-induced change within the creative revision process affects, and in turn is affected by, feedback recipients' identities. Scholars have argued that individuals' self-concepts are at least partly informed by psychological ownership over the objects of their work (Baer \& Brown, 2012; Rouse, 2013) and the socially defined roles related to that work (e.g., inventors; Cardon, Wincent, Singh, 
\& Drnovsek, 2009). Current theorizing related to creative revision, however, does not focus on identity in the context of this process. Instead, it focuses largely on the informational aspects of creative revision, whereby individuals seek out feedback to help reduce environmental uncertainties and information asymmetries that may cause others to challenge the presumed novelty and usefulness of the ideas (Harrison \& Rouse, 2015; Perry-Smith \& Mannucci, 2015). This neglects a problem illustrated in the opening epigraphs and common to creative work, wherein individuals are concerned by, if not resistant to, externally imposed changes to their creative ideas (Crilly, 2017). These changes, while likely intended to increase an idea's viability, might paradoxically undermine it by challenging individuals' associated identity-based relationships to their work. Consequently, although design thinking, business model development, prototyping, and lean start-up practices have flourished as practical templates for creative revision, insufficient theory exists about how individuals embrace change originating from external sources without destabilizing their identities.

The findings of this study highlight this overlooked aspect of the creative revision process: the psychological ownership of ideas shapes how individuals respond to feedback, requiring them to reconsider both their ideas and identities. Moreover, the findings reveal the importance of collective sensemaking and individuals' prior creative experience in further conditioning this process. The emergent model makes several theoretical contributions that extend and challenge prior scholarship on both creative work and founder identities. Most notably, the findings suggest that creative revision is a process wherein founders or other creative workers attempt not only to advance the novelty and usefulness of their ideas by aligning their work with external demands, but also to retain a sense of self and subjective meaning. Practically, this insight is important because it suggests that, in order to increase the viability of creative outputs, participants in the creative revision process must balance demands for adaptation with the need to retain a coherent sense of self and purpose.

\section{CREATIVE REVISION: ACCOUNTING FOR THE INTERSECTION OF IDEA AND IDENTITY WORK}

The processes of creative revision and identity reconstruction are ubiquitous and important in the context of organizing. Although they are related, most researchers have treated them as separate issues in prior scholarship. The former is largely understood to entail "idea work"-efforts to enhance the novelty and usefulness of an idea (i.e., the cognitive representation of a creative solution) and its associated creative outputs (Carlsen, Clegg, \& Gjersvik, 2012; Harrison \& Rouse, 2015; Perry-Smith \& Mannucci, 2015). Studies have increasingly examined how creative revision is socially embedded, triggered, and influenced by interactions between creative workers and external feedback providers rather than by ideas generated during isolated and independent brainstorming sessions (Hargadon \& Bechky, 2006; Perry-Smith, 2006; Perry-Smith \& Shalley, 2003). Such social interaction and feedback is common in organizations, particularly entrepreneurial start-ups (Perry-Smith \& Coff, 2011; Rouse, 2013). The latter process, which involves efforts to reconstruct and present one's identity in ways that enhance self-efficacy, is commonly labeled as "identity work" (Kreiner, Hollensbe, \& Sheep, 2006; Pratt, Rockmann, \& Kaufmann, 2006). Given individuals' tendencies under routine conditions to reinforce rather than proactively change existing identities (Burke \& Reitzes, 1981, 1991), the practices associated with identity work are again often understood to be triggered by external events or demands that destabilize individuals' identities (Beech, Gilmore, Cochrane, \& Greig, 2012; Koerner, 2014; Pratt et al., 2006).

Beyond the obvious involvement of idea work in creative revision, frequent external demands can destabilize not only perceptions of an idea's novelty and usefulness but also a creative worker's identity (Rouse, 2013). Although this process may simultaneously trigger both idea work and identity work, current theories of creative revision offer little insight into this potential practical and theoretical intersection. Specifically, there appear to be at least two potential practical tensions within the creative revision process. First, creative revision and the willingness to change an idea (i.e., "pivot") can be impeded by connections to specific earlier versions of the idea (Crilly, 2017). Second, feedback from resource providers can instigate idea-based change, which may create a sense of loss for creative workers (Baer \& Brown, 2012). These practical tensions also illuminate the potential intersection between idea work and identity work. If creative workers' connections to their ideas relate to their identities, resistance to idea-based change might be expected, and so might the need to reformulate those identities in the face of change. In the following subsections, 
I review the existing research on creative revision, noting how the important intersection between idea work and identity work has received scant attention.

\section{From Information Constraints to Identity Constraints}

A primary concern motivating existing studies of creativity, particularly in innovation and entrepreneurship contexts, is constraints that inhibit creative workers' efforts to ensure the novelty and usefulness of their creative outputs (Anderson, Potočnik, \& Zhou, 2014; Baer, 2012). Researchers mostly assume that informational deficiencies compromise the success of creative outputs, and focus on strategies for overcoming them. Consequently, they focus on sources (e.g., mentors, weak ties) and practices (e.g., prototyping, networking) that might increase feedback quality, thereby bolstering creative workers' access to information and improving the novelty and usefulness of ideas (Harrison \& Rouse, 2015; Ozgen \& Baron, 2007; Perry-Smith \& Mannucci, 2015; Sutton \& Hargadon, 1996).

While this scholarly emphasis on the relationship between creative revision and the novelty and usefulness of creative work is crucially important, in practice, creative work often is perceived as a highly personal endeavor rather than an instrumental one. First, audiences are prone to evaluate and categorize not only creative ideas or prototypes, but also the creative potential of those who generate them (Elsbach \& Kramer, 2003; Stevens \& Kristof, 1995). Second, creative workers often attach great weight to their own personal evaluations of and connections to an idea (Baer \& Brown, 2012; Brown \& Baer, 2015), which ultimately can be at odds with the instrumental goal of accommodating external feedback. Davies and Talbot (1987: 20), for example, conducted a series of interviews with designers in the United Kingdom who had been recognized as Royal Designers for Industry about their relationships to their ideas:

These designers described experiences in which they realised an idea was exactly right. It was the idea. It was not tentative ... but final. Realising the idea as a concrete object did not involve elaboration and validation of a tentative idea.

The designers viewed the ideas as "theirs," and offered their own appraisals of those ideas as "exactly right." Given such personal evaluations, even feedback targeted at ideas or tasks rather than the people associated with them might be taken personally. This reaction may then become a constraint on the creative revision process, compromising the designers' willingness to elaborate or validate their ideas, which would imply treating them instead as tentative "works in progress."

Two streams of research offer some initial insight into the basis of this constraint-namely, the literatures on psychological ownership and role identity. Regarding the first, "psychological ownership" has been defined as "that state in which individuals feel as though the target of ownership (material or immaterial in nature) or a piece of it is 'theirs"' (Pierce, Kostova, \& Dirks, 2001: 299). According to this research, psychological ownership over an intangible or immaterial item such as a creative idea is likely to increase as one develops deeper knowledge about the idea, invests time and energy in it, and perceives control over it (Pierce et al., 2001). In developing such ownership, ideas can become viewed by creative workers as extensions of the self, contributing to their identities and self-efficacy (Belk, 1988; Pierce, Kostova, \& Dirks, 2003). Psychological ownership thereby decreases individuals' willingness to relinquish control over those ideas (Brown, Lawrence, \& Robinson, 2005; Rouse, 2013). Hence, individuals' psychological ownership of ideas might challenge their willingness to revise them in response to external feedback.

Second, research on role identities suggests that individuals internalize particular identity standards related to specific roles or positions within a social structure (Stryker \& Burke, 2000). As an individual engages in activities associated with a particular role and becomes committed to the associated networks and relationships, the identity salience of that role increases (Stryker \& Serpe, 1982). This in turn produces more consistent engagement with objects and activities typically associated with that role (Burke \& Reitzes, 1991). For instance, in the context of entrepreneurship, individuals who view the role of inventor as salient to their identities are likely to consistently engage in and derive meaning and positive affect from the cognitive efforts involved in formulating entrepreneurial ideas (Mathias \& Williams, 2017). Cardon and her colleagues (2009: 520) argued that such positive affect linked to founders' enactment of identity-salient roles, which they labeled "entrepreneurial passion," might "limit an entrepreneur's creative problem solving" and make them "resistant to exploring alternative options." Thus, creative workers' commitments to particular role identities associated with creating new ideas may ultimately constrain the creative revision process. 
Although these two literatures diverge in focus, they both offer arguments and evidence suggesting that individuals' self-concepts might constrain the creative revision process. Therefore, responding to demands to revise their ideas may require creative workers to resolve any consequent instability in their identities.

\section{Creative Revision amid External Demands Requires Subsequent Identity Work}

Although the literatures on creative revision and identity work have developed independently, both emphasize the importance of feedback along with external social conditions in triggering each of the respective processes. First, research on creative revision has exposed several different practices used by feedback providers to suggest changes to ideas or other creative inputs (Harrison \& Rouse, 2015). Baer and Brown (2012) notably suggested that feedback varies in terms of both rhetorical content and intentions relative to the creative ideas or inputs. Specifically, they argued that feedback can be "additive," with suggestions to build on individuals' existing ideas, or "subtractive," with suggestions to strip away elements of those ideas. The authors conducted two experiments in which they asked participants to develop a promotional strategy for a restaurant. In the scenario in which they proposed subtractive changes to the target customer segments, the participants with greater psychological ownership of the ideas experienced a strong sense of loss and negative affect.

Research on identity work is similarly focused on the effects of externally imposed change (Beech et al., 2012; Elsbach \& Flynn, 2013; Kreiner et al., 2006). Studies in this area are grounded in social identity theory (Tajfel \& Turner, 1979; Turner, Hogg, Oakes, Reicher, \& Wetherell, 1987), wherein it is argued that individuals' personal identities (i.e., differentiating characteristics) are subject to potential tensions associated with the demands of their social identities (i.e., categorizations of the self into social groups; Brewer, 1991; Kreiner et al., 2006). When specific occupational demands or social conditions violate or threaten individuals' identities within the context of their labor (Petriglieri, 2011), this is presumed to trigger a process of identity work, allowing individuals to "come to terms with" those violations, often by way of small adjustments to how they make sense of their identities vis-à-vis the infringing social conditions (Pratt et al., 2006). Within the context of creative work, for example, Elsbach
(2009) studied designers whose activities were constantly constrained by their corporate employers. She found that the designers engaged in identity work, developing individual creative or "signature" styles that enabled them to retain their distinctiveness despite corporate constraints and pressures for conformity.

Taken together, these separate research streams establish the importance of both idea work and identity work within the context of the creative process. While no studies to date have considered the two types of work in tandem, related studies seem to support the premise that, when changes to ideas are externally imposed, identity work is likely to be required of individuals who regard aspects of those ideas as salient to their identities. To develop new theory, researchers must explore this intersection to illustrate how ideas change in response to feedback and how these changes affect creative workers' identities. In this study, I consider how idea work shapes identity work; in doing so, I also consider the feedback context and creative workers' experience-based differences that contribute to variations in this process.

\section{RESEARCH METHODS}

Given the lack of existing research at the intersection of idea and identity work, I used an inductive, grounded theory approach (Fendt \& Sachs, 2008; Locke, 2001; Strauss \& Corbin, 1990). This approach is well suited for understanding how founders "go about constructing and understanding their experiences" (Gioia, Corley, \& Hamilton, 2013: 16) as they encounter difficult feedback, change their ideas, and reconsider their identity-based relationships to their creative work.

\section{Sampling}

I conducted an extensive eight-month field study of 59 founders and their feedback providers, using data from serial interviews, non-participant observations, and archival documentation. I relied on purposive sampling (Patton, 2002; Yin, 2009) because I was primarily concerned with identifying sites and study participants most likely to reveal instances wherein (a) idea-based change was instigated by external sources, and (b) the affected ideas were likely to be deemed salient to the identities of the creative workers. With regard to site selection, I initially identified contexts that offered the most efficient access to frequent and consequential feedback 
interactions between resource-constrained founders and potential resource providers. As such, I negotiated access to two entrepreneurial incubators (both in the same region of the United States) with concentrated pools of resource-constrained founders who were gathering feedback about their ideas while attempting to find the resources to commercialize them.

Within these contexts, I sought out founders who were actively pursuing feedback and capital investment opportunities, and who were early enough in the commercialization process (e.g., pre-revenue, pre-capital investment) that feedback was particularly meaningful, since it often was couched within the context of resource acquisition. I also selected founders who had been directly involved in generating the ideas and launching the ventures they were pursuing, since such direct involvement can lead to high levels of psychological ownership (Pierce et al., 2001). For ventures with founding teams, I treated each founder as a separate case. In other words, while I also attended to possible effects of peer-group dynamics on the process of creative revision, my analytical unit of analysis was the founder and his or her practices.

My primary sample comprised 26 ongoing incubator residents whom I observed and interviewed frequently. When I started my study, 15 of these participants had just been accepted into a 14-week program designed to accelerate customer development and capital acquisition. I was thus able to observe and interview these founders throughout the entire course of their involvement with the incubator.

Having been granted access to the incubators' documentation, I selected another 28 founders affiliated with (but who had not applied to be residents of) the incubators. As such, their interactions with the incubators were limited to irregular mentorship sessions with domain experts associated with the incubators. To further test whether incubator involvement of any sort was an important boundary condition, I also used convenience sampling to select five more founders with no exposure to the incubators and with whom I was personally familiar. In all of these cases, selection criteria mirrored those for the primary sample, ensuring that founders from both my primary and secondary samples were exposed to similar types of feedback with similar stakes. These additional participants described feelings of ownership over their creative ideas (i.e., "my idea"), providing evidence to support and further develop insights from the incubator context.
Thus, I opted to include this sample and the additional data I collected as a part of my overall analysis of the creative revision process.

\section{Data Collection}

I engaged in triangulated data collection (Denzin \& Lincoln, 1994; Eisenhardt, 1989; Yin, 2009) using three different sources: semi-structured interviews, observations, and documentation. I conducted 103 interviews with an average duration of 30 minutes. During these interviews, I focused on surfacing the participants' experiences related to idea development, feedback interactions, and subsequent changes to their ideas, as well as their ongoing relationships to their creative work.

While the interviews provided indirect access to multiple accounts of feedback across the primary and secondary samples, most direct observations of feedback involved the primary sample of founders in residence at the incubators. Specifically, I observed 17 pitch events as well as 10 private (i.e., closeddoor) and five semi-private (i.e., within a public meeting space) mentoring sessions, resulting in more than three months' worth of field notes and 36 hours of recorded and transcribed audio files. Finally, I collected 213 pages of notes taken by mentors during their feedback interactions with founders from both the primary and secondary samples, 20 pages of qualitative peer evaluations, six business plans, eight pitch decks, and sundry marketing collateral and business modeling artifacts. I gathered this documentation to ensure that I was not missing any important "behind the scenes" interactions. Founders in the primary sample relied heavily on a tool called the "Business Model Canvas" (Osterwalder \& Pigneur, 2010), which enabled them to document their assumptions about how their entrepreneurial ideas would create value. Thus, I was able to capture data on the evolution of the founders' ideas and underlying assumptions. Table 1 outlines the various data collection methods and the consequent data inventory.

\section{Data Analysis}

I analyzed the data using the constant comparative method, consistent with Strauss and Corbin (1990) as well as Gioia, Corley, and Hamilton (2013). First, I used the terms frequently employed by participants during both observations and interviews to surface first-order codes (Van Maanen, 1979). For instance, the first-order codes related to changes in the ideas 
TABLE 1

Data Inventory

\begin{tabular}{|c|c|c|c|}
\hline Data type & Quantity & Original data source & Original (intended) data audience \\
\hline \multirow[t]{2}{*}{$\begin{array}{c}\text { Entrepreneur } \\
\text { interviews }\end{array}$} & $\begin{array}{l}\text { Primary sample: } 30+\text { hours of recorded } \\
\text { and transcribed audio from } 69 \\
\text { interviews (captured } 93 \text { separate } \\
\text { instances of feedback responses) }\end{array}$ & $\begin{array}{l}\text { Primary sample: } 26 \text { incubator } \\
\text { residents (19 of which had } \\
\text { cofounders) }\end{array}$ & Researcher \\
\hline & $\begin{array}{l}\text { Secondary sample: } 20+\text { hours of } \\
\text { recorded and transcribed audio from } \\
34 \text { interviews (captured } 50 \text { separate } \\
\text { instances of feedback responses) }\end{array}$ & $\begin{array}{l}\text { Secondary sample: } 33 \text { incubator } \\
\text { affiliates/incubator non-affiliates } \\
\text { (10 of which had cofounders) }\end{array}$ & \\
\hline $\begin{array}{l}\text { Stakeholder } \\
\text { interviews }\end{array}$ & $\begin{array}{l}7+\text { hours of recorded and transcribed } \\
\text { audio from } 12 \text { interviews }\end{array}$ & $\begin{array}{l}2 \text { incubator directors, } 10 \text { business } \\
\text { mentors }\end{array}$ & Researcher \\
\hline $\begin{array}{l}\text { Observational } \\
\text { data }\end{array}$ & $\begin{array}{l}\text { Primary sample: } 36+\text { hours of recorded } \\
\text { and transcribed audio; } 14 \text { weeks of } \\
\text { non-recorded on-site observation of } \\
\text { feedback exchanges and creative } \\
\text { revision in an incubator }\end{array}$ & $\begin{array}{l}\text { Audio and researcher's notes from } \\
17 \text { “pitch events,” } 10 \text { private } \\
\text { mentoring sessions, and } 5 \text { semi- } \\
\text { private mentoring sessions }\end{array}$ & Researcher \\
\hline $\begin{array}{l}\text { Other } \\
\text { documentation }\end{array}$ & $\begin{array}{l}\text { Primary sample: } 70 \text { business model } \\
\text { canvases; } 20 \text { pages of quantitative } \\
\text { peer evaluations; } 6 \text { business plans; } \\
3 \text { investor "one-sheets"/executive } \\
\text { summaries; } 8 \text { "pitch decks"; } \\
1 \text { "customer letter of intent" }\end{array}$ & $\begin{array}{l}\text { Primary sample: } 26 \text { incubator } \\
\text { residents }\end{array}$ & $\begin{array}{l}\text { Business stakeholders (i.e., } \\
\text { investors, customers, } \\
\text { employees, mentors, and } \\
\text { partners) }\end{array}$ \\
\hline
\end{tabular}

included words and phrases that conveyed both the degree of change as well as specific aspects requiring revision (e.g., "overhaul the model" vs. "tweak the cost structure"). During this phase, I also coded words and phrases that deepened my understanding of the feedback context, such as rhetorical differences in the feedback, forum type (e.g., public or private), the number of people in attendance, and whether or not the founders discussed their feedback with peers following the session.

Once the first-order coding efforts failed to reveal additional unique terms and references of potential importance, I concluded that I had reached data saturation. Specifically, each of the first-order codes included in later stages of my analysis were present in at least five of the 59 observed cases, providing numerous examples from which to engage in axial coding. This second step of axial coding involved comparing similar first-order codes (e.g., references to "my idea," as well as personal narratives that conveyed a sense of control over an idea or investments of time, energy, and values into it). This step enabled me to surface the characteristics of broader categories of data known as second-order themes. Each of the second-order themes included in my final analysis were present in at least 11 of the 59 observed cases, again providing numerous examples from which to understand the steps involved in the creative revision process.

Finally, the third step involved attempts to refine the categories and themes into a model of creative revision that accounted for tensions between changes in the ideas and founders' relationships to those ideas, as well as the overarching feedback context. This step in the analysis is known as "selective coding," and the aim is to identify relationships between different core categories. In this step, I engaged in "temporal bracketing" (Langley, 1999), whereby I segmented feedback episodes and clustered them by founder. Such an approach improves comparison and replication for theory-building purposes (Denis, Dompierre, Langley, \& Rouleau, 2011). Each episode thus comprised the initial feedback, subsequent efforts to process and make sense of that feedback, and practices aimed at revising the founder's idea and identity. Such temporal bracketing enabled me to understand the sequential arrangement of steps in this process and the 
mechanisms connecting them. Clustering these episodes by founder, I was then able to perceive how these "discrete but connected blocks" (Langley, 1999: 703) highlighted patterns within each case as well as across cases (Eisenhardt \& Graebner, 2007). Table 2 presents these and other patterns across my cases, which supplement my in-depth analyses within cases and lead to further insights about the relationships between the various themes.

For instance, 26 participants in my sample were incubator residents and 29 were part of cofounding teams. As I explored the contextual differences between founders in my sample, I found the collective sensemaking that ensued after feedback exchanges to be among the critical factors shaping founders' reappraisals of psychological ownership. Following Corley and Gioia's (2004) illustrative visualization of qualitative data structures, Figure 1 highlights the relationships between the final first-order concepts, second-order themes, and aggregate dimensions that emerged from my analysis.

\section{RESEARCH FINDINGS}

To situate the reporting of findings related to the inductive model surfaced in this study, I begin this section by providing evidence of the founders' initial ideas and their identity-based connections to particular facets of those ideas as well as to the inventor role. I then discuss the feedback that triggered the identity-informed process of creative revision. The main focus of the findings section is oriented toward highlighting the entrepreneurs' responses-how they reappraised their psychological ownership of ideas, the constraints this imposed on subsequent idea and identity work, and the effects on the ability to achieve a sense of optimal distinctiveness within the local entrepreneurial community. Table 3 provides additional evidence for each of these themes, and Figure 2 illustrates the observed relationships comprising the emergent model.

\section{Entrepreneurs and Their Ideas}

Upon meeting the participants in my study, I first asked them to tell me about their ideas. Their responses suggested that it was very difficult for them to convey their ideas to me or others without referencing personal experiences. The entrepreneurs consistently referred to particular moments in time in which the ideas were "sparked" or "birthed." One first-time entrepreneur in the digital media space employed both metaphors as he described the conception of his entrepreneurial idea:

So, this was the original spark for the idea ... Just having this moment of recognizing that people all over the world had the same challenge ... That was sort of the birth of this. (F27) ${ }^{1}$

Regardless of the origins, the entrepreneurs regarded these ideas not just as creative projects tied to abstract economic opportunities, but as reflections of their personal values and beliefs, which ultimately contributed to a sense of psychological ownership. The same founder quoted above, for example, reflected on how the idea and even the industry needed to appeal to him on a deep, personal level in order that he could truly feel like the project was worthwhile:

I wasn't about to start a biomedical or an aerospace company, or something that I wasn't passionate about. It had to be something that I believed in. It had to be an idea I could call my own. (F27)

When I pushed for clarification, founders indicated that they viewed their proposed solutionsand, by extension, the specific problems they had identified-as core to their ideas, and thus personally meaningful. The following interview exchange with a different entrepreneur illustrates this:

F18: If it's just interesting, that's not enough. You don't want to go to war for something that's just interesting. You want to go to war for something that ... is kind of core to how you see the world.

INTERVIEWER: So, what is it about your idea that you perceive to be core to how you see the world?

F18: Well, I think it starts with the solution that I am proposing for specific problems that I see with the delivery and provision of health care today.

For all entrepreneurs in the sample, it was clear that, while psychological ownership of their ideas positively compelled their creative work, such ownership also had the potential to constrain their ability to respond to feedback. One mentor who had delivered feedback to many entrepreneurs summarized this constraint:

You know, [many founders] have got very fixed ideas about what's right and wrong with the world and they're not going to compromise their values so that some investor can just make money. They're after the purity of their ideas.

\footnotetext{
${ }^{1}$ This citation convention identifies founders in correspondence with Table 2.
} 
TABLE 2

Patterns of Creative Revision

\begin{tabular}{|c|c|c|c|c|c|c|c|c|}
\hline Founder & $\begin{array}{c}\text { Initial psych. } \\
\text { ownership } \\
\text { of the idea }\end{array}$ & Cofounder & $\begin{array}{c}\text { Incubator } \\
\text { resident }\end{array}$ & $\begin{array}{c}\text { Incubator } \\
\text { affiliate }\end{array}$ & $\begin{array}{c}\text { Prior } \\
\text { experience }\end{array}$ & $\begin{array}{c}\text { Psychological } \\
\text { ownership }\end{array}$ & $\begin{array}{c}\text { Idea work } \\
\text { practice }\end{array}$ & $\begin{array}{c}\text { Identity } \\
\text { work } \\
\text { practice }\end{array}$ \\
\hline 1 & $\mathrm{Y}$ & $\mathrm{Y}$ & $\mathrm{Y}+$ & $\mathrm{N}$ & S & $\mathrm{Ab}$ & Rp, Df & Dec \\
\hline 2 & $\mathrm{Y}$ & $\mathrm{Y}$ & $\mathrm{Y}+$ & $\mathrm{N}$ & $\mathrm{S}$ & $\mathrm{Ab}$ & Rp, Df & Dec \\
\hline 3 & $\mathrm{Y}$ & $\mathrm{Y}$ & $\mathrm{Y}+$ & $\mathrm{N}$ & $\mathrm{S}$ & $\mathrm{Ab}$ & $\mathrm{Rp}, \mathrm{Df}$ & Dec \\
\hline 4 & $\mathrm{Y}$ & $\mathrm{Y}$ & $\mathrm{Y}+$ & $\mathrm{N}$ & $\mathrm{G}$ & Rl & $\mathrm{Rn}$ & $\mathrm{P}$ \\
\hline 5 & $\mathrm{Y}$ & $\mathrm{Y}$ & $\mathrm{Y}+$ & $\mathrm{N}$ & G & $\mathrm{Rl}$ & $\mathrm{Rn}$ & $\mathrm{P}$ \\
\hline 6 & $\mathrm{Y}$ & $\mathrm{Y}$ & $\mathrm{Y}+$ & $\mathrm{N}$ & $\mathrm{S}$ & $\mathrm{Rl}$ & $\mathrm{Rn}$ & $\mathrm{P}$ \\
\hline 7 & $\mathrm{Y}$ & $\mathrm{Y}$ & $\mathrm{Y}+$ & $\mathrm{N}$ & G & $\mathrm{Rl}$ & $\mathrm{Rn}$ & $\mathrm{P}$ \\
\hline 8 & $\mathrm{Y}$ & $\mathrm{N}$ & $\mathrm{Y}+$ & $\mathrm{N}$ & $\mathrm{S}$ & $\mathrm{Rf}$ & Df & $\mathrm{T}$ \\
\hline 9 & $\mathrm{Y}$ & $\mathrm{Y}$ & $\mathrm{Y}+$ & $\mathrm{N}$ & S & $\mathrm{Ab}$ & $\mathrm{Rp}, \mathrm{Df}$ & Dec \\
\hline 10 & $\mathrm{Y}$ & $\mathrm{Y}$ & $\mathrm{Y}+$ & $\mathrm{N}$ & G & $\mathrm{Ab}$ & Rp, Df & Dec \\
\hline 11 & $\mathrm{Y}$ & $\mathrm{Y}$ & $\mathrm{Y}+$ & $\mathrm{N}$ & G & $\mathrm{Rl}$ & $\mathrm{Rn}$ & $\mathrm{P}$ \\
\hline 12 & $\mathrm{Y}$ & $\mathrm{Y}$ & $\mathrm{Y}+$ & $\mathrm{N}$ & S & Rl & $\mathrm{Rn}$ & $\mathrm{P}$ \\
\hline 13 & $\mathrm{Y}$ & $\mathrm{Y}$ & $\mathrm{Y}+$ & $\mathrm{N}$ & $\mathrm{S}$ & $\mathrm{Ab}$ & $\mathrm{Rp}$ & Dec \\
\hline 14 & $\mathrm{Y}$ & $\mathrm{Y}$ & $\mathrm{Y}+$ & $\mathrm{N}$ & $\mathrm{S}$ & $\mathrm{Ab}$ & Rp & Dec \\
\hline 15 & $\mathrm{Y}$ & $\mathrm{Y}$ & $\mathrm{Y}+$ & $\mathrm{N}$ & S & $\mathrm{Ab}$ & Rp & Dec \\
\hline 16 & $\mathrm{Y}$ & $\mathrm{N}$ & $\mathrm{Y}$ & $\mathrm{N}$ & $\mathrm{S}$ & $\mathrm{Rf}$ & Df & $\mathrm{T}$ \\
\hline 17 & $\mathrm{Y}$ & $\mathrm{N}$ & $\mathrm{N}$ & $\mathrm{Y}$ & $\mathrm{S}$ & $\mathrm{Rf}$ & $\mathrm{Df}$ & $\mathrm{T}$ \\
\hline 18 & $\mathrm{Y}$ & $\mathrm{N}$ & $\mathrm{Y}$ & $\mathrm{N}$ & S & $\mathrm{Ab}$ & Rp, Df & Dec \\
\hline 19 & $\mathrm{Y}$ & $\mathrm{Y}$ & $\mathrm{Y}$ & $\mathrm{N}$ & S & Rl & Rn, Rp, Df & $\mathrm{P}$ \\
\hline 20 & $\mathrm{Y}$ & $\mathrm{Y}$ & $\mathrm{Y}$ & $\mathrm{N}$ & S & Rl & Rn, Rp, Df & $\mathrm{P}$ \\
\hline 21 & $?$ & $\mathrm{~N}$ & $\mathrm{~N}$ & $\mathrm{Y}$ & $\mathrm{G}$ & $\mathrm{Ab}$ & $\mathrm{Rp}$ & $\mathrm{P}$ \\
\hline 22 & $\mathrm{Y}$ & $\mathrm{N}$ & $\mathrm{Y}$ & $\mathrm{N}$ & S & $\mathrm{Rf}$ & Df & $\mathrm{T}$ \\
\hline 23 & $?$ & $\mathrm{~N}$ & $\mathrm{~N}$ & $\mathrm{Y}$ & $\mathrm{G}$ & $\mathrm{Rl}$ & $\mathrm{Rn}, \mathrm{Rp}$ & $\mathrm{P}$ \\
\hline 24 & $\mathrm{Y}$ & $\mathrm{N}$ & $\mathrm{Y}$ & $\mathrm{N}$ & $\mathrm{G}$ & $\mathrm{Ab}$ & $\mathrm{Rp}$ & Dec \\
\hline 25 & $\mathrm{Y}$ & $\mathrm{N}$ & $\mathrm{Y}$ & $\mathrm{N}$ & $\mathrm{S}$ & $\mathrm{Rf}$ & $\mathrm{Df}$ & $\mathrm{T}$ \\
\hline 26 & $\mathrm{Y}$ & $\mathrm{Y}$ & $\mathrm{Y}$ & $\mathrm{N}$ & S & $\mathrm{Ab}$ & Rp, Df & Dec \\
\hline 27 & $\mathrm{Y}$ & $\mathrm{N}$ & $\mathrm{Y}$ & $\mathrm{N}$ & G & $\mathrm{Ab}$ & $\mathrm{Rp}$ & Dec \\
\hline 28 & $\mathrm{Y}$ & $\mathrm{N}$ & $\mathrm{Y}$ & $\mathrm{N}$ & G & Rl & Rn, Rp, Df & $\mathrm{P}$ \\
\hline 29 & $\mathrm{Y}$ & $\mathrm{Y}$ & $\mathrm{N}$ & $\mathrm{Y}$ & S & $\mathrm{Ab}$ & $\mathrm{Rp}$ & Dec \\
\hline 30 & $\mathrm{Y}$ & $\mathrm{Y}$ & $\mathrm{N}$ & $\mathrm{N}$ & S & $\mathrm{Rf}$ & Df & $\mathrm{T}$ \\
\hline 31 & $\mathrm{Y}$ & $\mathrm{N}$ & $\mathrm{Y}$ & $\mathrm{N}$ & S & $\mathrm{Rf}$ & Df & $\mathrm{T}$ \\
\hline 32 & $\mathrm{Y}$ & $\mathrm{N}$ & $\mathrm{N}$ & $\mathrm{Y}$ & $\mathrm{G}$ & $\mathrm{Rl}$ & $\mathrm{Rn}$ & $\mathrm{P}$ \\
\hline 33 & $\mathrm{Y}$ & $\mathrm{N}$ & $\mathrm{N}$ & $\mathrm{Y}$ & $\mathrm{S}$ & $\mathrm{Rf}$ & Df & $\mathrm{T}$ \\
\hline 34 & $\mathrm{Y}$ & $\mathrm{Y}$ & $\mathrm{N}$ & $\mathrm{N}$ & $\mathrm{S}$ & $\mathrm{Rl}$ & Rn, Rp, Df & $\mathrm{P}$ \\
\hline 35 & $\mathrm{Y}$ & $\mathrm{Y}$ & $\mathrm{N}$ & $\mathrm{N}$ & S & $\mathrm{Rl}$ & Rn, Rp, Df & $\mathrm{P}$ \\
\hline 36 & $\mathrm{Y}$ & $\mathrm{Y}$ & $\mathrm{N}$ & $\mathrm{Y}$ & $\mathrm{S}$ & $\mathrm{Rl}$ & $\mathrm{Rn}$ & $\mathrm{P}$ \\
\hline 37 & $\mathrm{Y}$ & $\mathrm{Y}$ & $\mathrm{N}$ & $\mathrm{Y}$ & $\mathrm{S}$ & $\mathrm{Rl}$ & $\mathrm{Rn}$ & $\mathrm{P}$ \\
\hline 38 & $\mathrm{Y}$ & $\mathrm{N}$ & $\mathrm{N}$ & $\mathrm{Y}$ & $\mathrm{S}$ & $\mathrm{Rf}$ & Df & $\mathrm{T}$ \\
\hline 39 & $\mathrm{Y}$ & $\mathrm{N}$ & $\mathrm{N}$ & $\mathrm{Y}$ & G & $\mathrm{Ab}$ & $\mathrm{Rp}$ & Dec \\
\hline 40 & $\mathrm{Y}$ & $\mathrm{Y}$ & $\mathrm{N}$ & $\mathrm{Y}$ & S & $\mathrm{Rf}$ & Df & $\mathrm{T}$ \\
\hline 41 & $\mathrm{Y}$ & $\mathrm{N}$ & $\mathrm{N}$ & $\mathrm{Y}$ & G & $\mathrm{Ab}$ & $\mathrm{Rp}$ & Dec \\
\hline 42 & $\mathrm{Y}$ & $\mathrm{N}$ & $\mathrm{N}$ & $\mathrm{Y}$ & S & $\mathrm{Rf}$ & $\mathrm{Df}$ & $\mathrm{T}$ \\
\hline 43 & $\mathrm{Y}$ & $\mathrm{N}$ & $\mathrm{N}$ & $\mathrm{Y}$ & S & $\mathrm{Rf}$ & $\mathrm{Df}$ & $\mathrm{T}$ \\
\hline 44 & $\mathrm{Y}$ & $\mathrm{Y}$ & $\mathrm{N}$ & $\mathrm{Y}$ & $\mathrm{S}$ & $\mathrm{Rf}$ & $\mathrm{Df}$ & $\mathrm{T}$ \\
\hline 45 & $\mathrm{Y}$ & $\mathrm{Y}$ & $\mathrm{N}$ & $\mathrm{Y}$ & $\mathrm{S}$ & $\mathrm{Ab}$ & $\mathrm{Rp}$ & Dec \\
\hline 46 & $?$ & $\mathrm{~N}$ & $\mathrm{~N}$ & $\mathrm{Y}$ & $\mathrm{S}$ & $\mathrm{Rl}$ & Rn, Rp & $\mathrm{P}$ \\
\hline 47 & $\mathrm{Y}$ & $\mathrm{N}$ & $\mathrm{N}$ & $\mathrm{Y}$ & S & $\mathrm{Rf}$ & Df & $\mathrm{T}$ \\
\hline 48 & $\mathrm{Y}$ & $\mathrm{N}$ & $\mathrm{N}$ & $\mathrm{Y}$ & $\mathrm{S}$ & $\mathrm{Rf}$ & $\mathrm{Df}$ & $\mathrm{T}$ \\
\hline 49 & $\mathrm{Y}$ & $\mathrm{N}$ & $\mathrm{N}$ & $\mathrm{N}$ & S & $\mathrm{Rf}$ & $\mathrm{Df}$ & $\mathrm{T}$ \\
\hline 50 & $\mathrm{Y}$ & $\mathrm{Y}$ & $\mathrm{N}$ & $\mathrm{Y}$ & $\mathrm{G}$ & $\mathrm{Rl}$ & $\mathrm{Rn}$ & $\mathrm{P}$ \\
\hline 51 & $?$ & $\mathrm{~N}$ & $\mathrm{~N}$ & $\mathrm{Y}$ & $\mathrm{G}$ & $\mathrm{Rl}$ & Rn, Rp, Df & $\mathrm{P}$ \\
\hline 52 & $\mathrm{Y}$ & $\mathrm{N}$ & $\mathrm{N}$ & $\mathrm{Y}$ & S & $\mathrm{Rf}$ & Df & $\mathrm{T}$ \\
\hline 53 & $\mathrm{Y}$ & $\mathrm{N}$ & $\mathrm{N}$ & $\mathrm{Y}$ & $\mathrm{S}$ & $\mathrm{Rf}$ & $\mathrm{Df}$ & $\mathrm{T}$ \\
\hline 54 & $\mathrm{Y}$ & $\mathrm{Y}$ & $\mathrm{N}$ & $\mathrm{Y}$ & $\mathrm{S}$ & $\mathrm{Rl}$ & $\mathrm{Rn}$ & $\mathrm{P}$ \\
\hline 55 & $\mathrm{Y}$ & $\mathrm{Y}$ & $\mathrm{N}$ & $\mathrm{Y}$ & $\mathrm{S}$ & $\mathrm{Rl}$ & $\mathrm{Rn}$ & $\mathrm{P}$ \\
\hline 56 & $\mathrm{Y}$ & $\mathrm{N}$ & $\mathrm{N}$ & $\mathrm{Y}$ & $\mathrm{S}$ & $\mathrm{Rf}$ & Df & $\mathrm{T}$ \\
\hline 57 & $\mathrm{Y}$ & $\mathrm{N}$ & $\mathrm{N}$ & $\mathrm{Y}$ & $\mathrm{S}$ & $\mathrm{Rl}$ & $\mathrm{Rn}, \mathrm{Rp}, \mathrm{Df}$ & $\mathrm{P}$ \\
\hline 58 & $\mathrm{Y}$ & $\mathrm{N}$ & $\mathrm{N}$ & $\mathrm{Y}$ & $\mathrm{S}$ & $\mathrm{Rl}$ & $\mathrm{Rn}$ & $\mathrm{P}$ \\
\hline 59 & $\mathrm{Y}$ & $\mathrm{N}$ & $\mathrm{N}$ & $\mathrm{N}$ & S & $\mathrm{Rf}$ & $\mathrm{Df}$ & $\mathrm{T}$ \\
\hline
\end{tabular}

Notes: $\mathrm{Y}=$ yes, $\mathrm{N}=$ no, $\mathrm{Y}+=$ residency via accelerator program. $\mathrm{G}=$ generalized, $\mathrm{S}=$ specialized. $\mathrm{Rf}=$ reaffirming, $\mathrm{Ab}=\mathrm{abstracting}, \mathrm{Rl}=$ relinquishing. $\mathrm{Df}=$ defending, $\mathrm{Rp}=$ repairing, $\mathrm{Rn}=$ re-engineering. $\mathrm{T}=$ transcending; $\mathrm{Dec}=$ decoupling; $\mathrm{P}=$ professionalizing. 
FIGURE 1

Data Structure

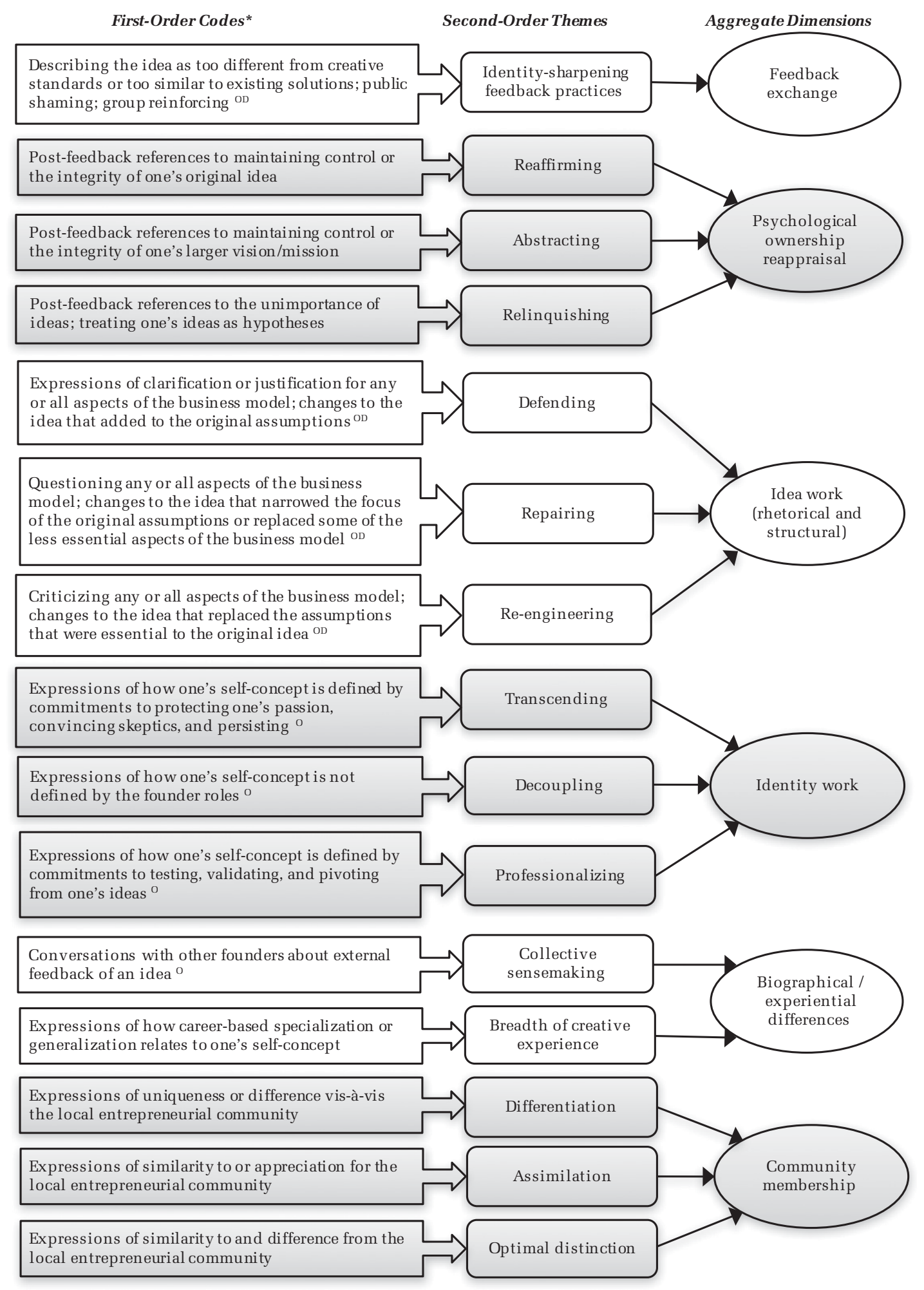

${ }^{\text {a }}$ All data were at least in part derived from semi-structured interviews.

$\mathrm{b}$ ' $\mathrm{O}$ ' indicates supplemented with observations.

c ' $D$ ' indicates supplemented with documentation. 
TABLE 3

Examples of Theoretical Dimensions and Second-Order Themes

\begin{tabular}{|c|c|c|}
\hline Aggregate dimension & $\begin{array}{l}\text { Second-order } \\
\text { theme }\end{array}$ & Exemplary quotes \\
\hline Feedback context & $\begin{array}{l}\text { Identity- } \\
\text { sharpening } \\
\text { feedback }\end{array}$ & $\begin{array}{l}\text { "You're missing a lot of very fundamental aspects that would make this } \\
\text { business investable." } \\
\text { "Why is this new? There's at least a half-dozen other companies doing this } \\
\text { right now." } \\
\text { "There are so many disjointed ideas floating around here that it's difficult to know } \\
\text { where to start. Is this an art project or is this a business? Because, if it's an art } \\
\text { project, then I guess this works. But, if you're trying to build a business, then you } \\
\text { really need to get clear on some fundamental things like who your customer } \\
\text { segment is and what their problem is and will they pay you to solve it." }\end{array}$ \\
\hline \multirow[t]{2}{*}{$\begin{array}{c}\text { Psychological } \\
\text { ownership }\end{array}$} & Initial & $\begin{array}{l}\text { (F33) "For me personally, the experience that I had was so moving and so life- } \\
\text { changing and so transformational that I said, 'I have to do this for a living, and I } \\
\text { have to share with other people what I went through, and I need to help other } \\
\text { people the way I was helped.' It's sort of like, 'I'm going to do this at all costs, and I } \\
\text { believe in my idea so passionately that I'm going to take } 20 \text { years of success and } \\
\text { experience that I have in one industry and set it aside."” }\end{array}$ \\
\hline & Abstracting & $\begin{array}{l}\text { (F24) "Oftentimes, they get confused. I originally mistook the vision and the idea as } \\
\text { kind of the same thing, but they're not always. My vision is more of my ethical } \\
\text { goal or something that I'm striving for, and the idea is usually the vehicle in trying } \\
\text { to achieve that vision, and I think a lot of people get confused by that, and they } \\
\text { hold onto their idea so strongly, and they think they're holding onto their vision." }\end{array}$ \\
\hline & Decoupling & $\begin{array}{l}\text { (F27) “There's this scientific model of how you do start-ups that's being taught, and I } \\
\text { suppose that's fine. I don't have a problem with that in general. But I think it's } \\
\text { been important for me to recognize that that's not why I'm here. I'm here because } \\
\text { this has been my vision for a really long time.” }\end{array}$ \\
\hline & Professionalizing & $\begin{array}{l}\text { (F36) "I used to think of myself as a salesman for this company and for the ideas } \\
\text { in my head, but I think it's more appropriate to think of my role in this process as a } \\
\text { scientist ... I'm out there systematically testing various concepts in the market." }\end{array}$ \\
\hline Idea work & Defending & $\begin{array}{l}\text { [Clarifying any or all aspects of the business model] (F30) "We just need to clarify } \\
\text { our story. For the next week, that's what we need to focus on-just nailing what } \\
\text { our algorithm will do... [The angel investors] weren't tracking, so we have to pull } \\
\text { that out for sure." } \\
\text { [Justifying any or all aspects of the business model] (F43) "Earlier this week I ran } \\
\text { a survey with my primary customer segment and 100\% of the respondents } \\
\text { said that they would pay for [my product] when it's released." } \\
\text { [Broadening any or all aspects of the business model] (F44) "I think what we're } \\
\text { starting with is fine, but users may need more features to justify paying money. I } \\
\text { think we need to spend some time considering what additional features we can } \\
\text { add to make this work ... I also think we can probably expand our intended } \\
\text { customer segment beyond just people in [this city]." }\end{array}$ \\
\hline
\end{tabular}


TABLE 3

(Continued)

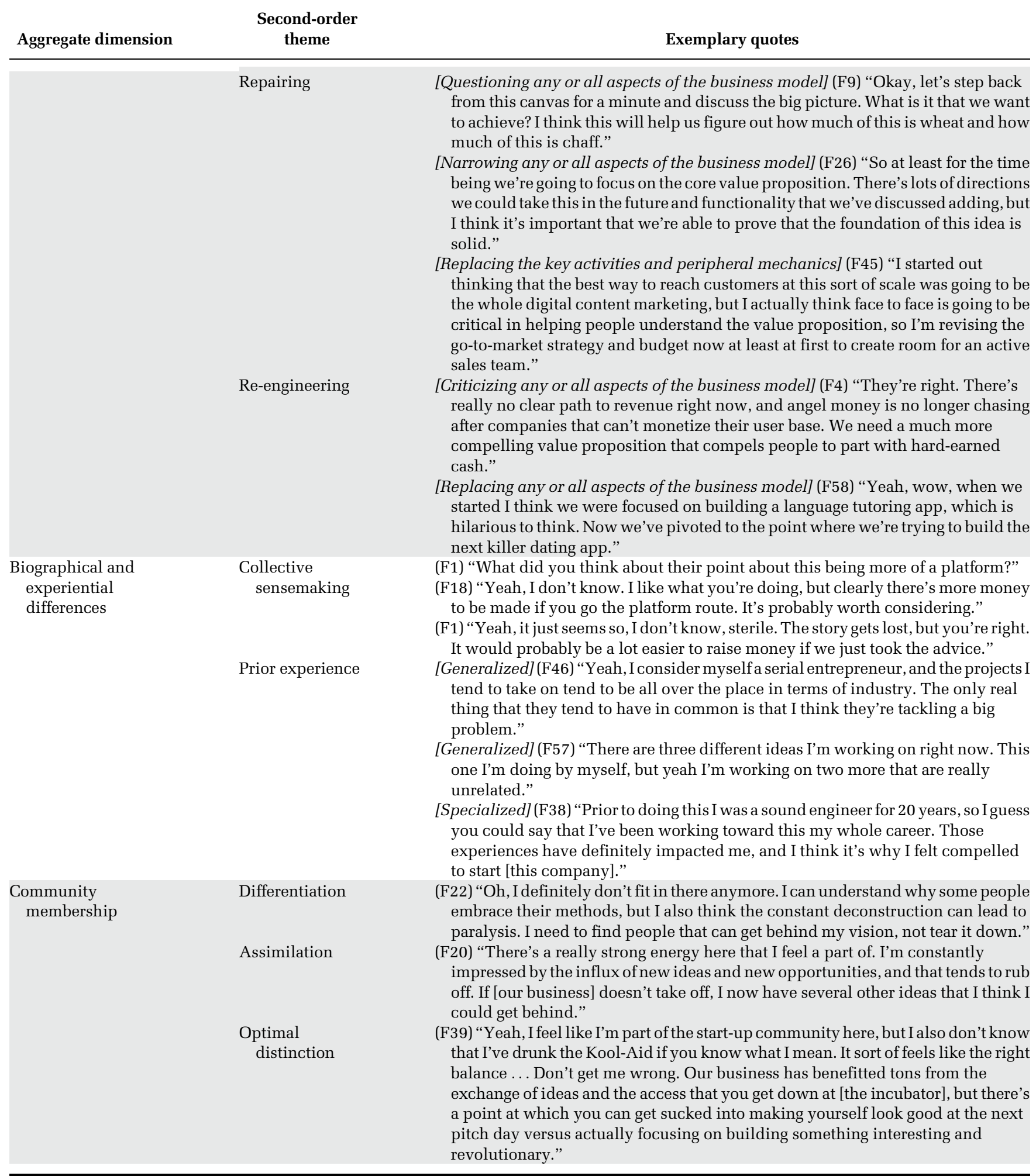


FIGURE 2

Identity-Based Process Model of Creative Revision

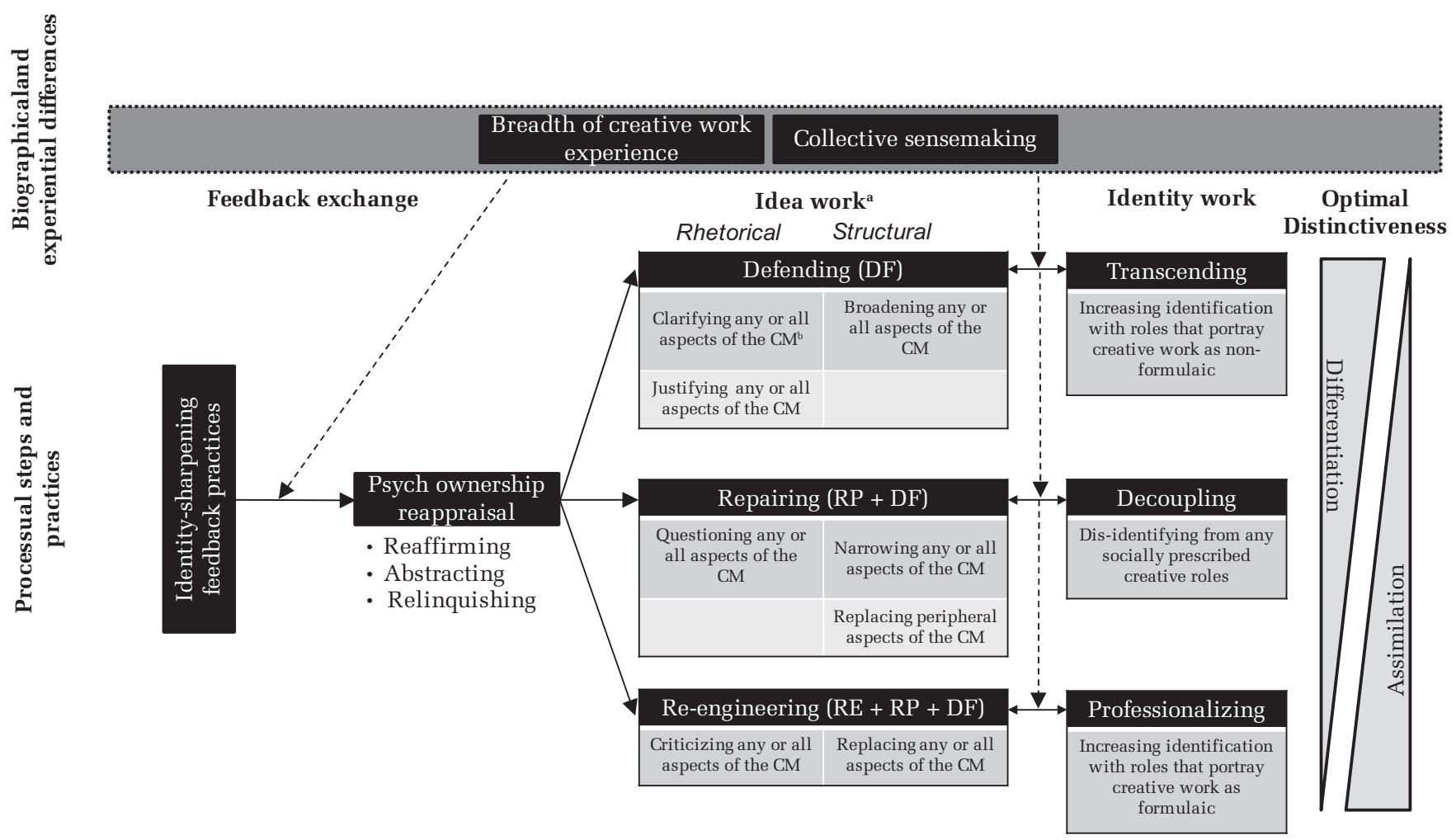

\footnotetext{
${ }^{\text {a }}$ Founders who engaged in more pronounced types of idea work also engaged in less pronounced types. This is indicated by the parenthetical notation next to the idea work labels.

${ }^{\mathrm{b}} \mathrm{CM}=$ creative model. The CM includes assumptions about: value proposition, customer segment/problem, key activities, and peripheral mechanics (i.e., customer channels and relationships, partnerships, resources, cost structure, revenue streams, "go to market" and growth strategies).
}

\section{Identity-Sharpening Feedback Practices}

"Identity-sharpening feedback practices" introduce a tension between creative workers' psychological ownership of their ideas and socially informed standards for creative output. Specifically, such feedback discounts the entrepreneurs' creative ideas as either too different from creative standards or too similar to ideas that have already been tested or established. For example, during the first pitch session I attended, one feedback provider suggested that the idea diverged too far from his creative standards, remarking: "I really don't understand the value proposition. I need to know what the customer problem is that you're trying to solve, and this is not remotely clear at this point." In another instance, a different feedback provider told a team of entrepreneurs that their idea too closely resembled ideas underpinning several already successful companies, stating: "[Your competitors] seem to already have a strong foothold on this emerging market and there are several other players as well."
Although the identity-sharpening feedback practices I observed exclusively targeted the creative ideas rather than the entrepreneurs, such practices primed founders' identity-based connections to their ideas by introducing reflected appraisals (i.e., information individuals perceive about themselves from others; Burke, 1991) that diverged from their own selfconcepts. As one entrepreneur explained:

It feels like sorority rush all over again, where they're making sweeping judgments about whether we belong here based on superficial details or a 30-second conversation. It's hard not to take that personally, when I know they're not understanding me or where we're coming from. (F14)

As such, these divergent creative standards and reflected appraisals that surfaced during the feedback process encouraged creative workers to not only revise their ideas, but also reflect on their identities. In this setting, such feedback practices contrasted with practices such as dialogic problem solving, which 
were less likely to trigger an identity-informed revision process.

\section{Psychological Ownership Reappraisal}

Following identity-sharpening feedback, entrepreneurs reappraised their psychological ownership in three different ways. First, several entrepreneurs reaffirmed psychological ownership of their ideas. Following a pitch session at one of the incubators, for example, I sat down with a founder to discuss the feedback he had received. He compared the feedback environment to the one depicted on a popular reality television show involving aspiring founders and angel investors:

Sometimes, when I go there, I feel like I'm on Shark Tank-you know, the TV show. [laughter] It's like one person stands up and torpedoes your idea and then everyone else smells blood and decides they want a piece. You saw it. [One potential investor] was basically, like, "Don't quit your day job, because this is going nowhere," and then [another potential investor] saw that as an opportunity to pile on ... But they're all just saying the same thing. And I'm just standing there thinking, "I've got a good idea! Just because you guys can't see what I see doesn't mean my idea isn't going to work." (F16)

Likewise, I met with another founder several days after he received identity-sharpening feedback wherein feedback providers questioned the need for the business he was proposing. This was the founder's first entrepreneurial venture, and, although he had already assembled a development team, during the early weeks, he processed feedback in isolation before involving team members. He explained:

So, I got to a point of almost feeling kind of desperate or lost, and I just got all my team together off-site, and I laid out what we were going to accomplish in those three hours. We were going to return to the original idea. We were going to talk about everything that inspires us about our idea, why we're involved, and why we've been giving ourselves to this to date. (F1)

These quotes illustrate founders' efforts to reaffirm psychological ownership of their ideas after receiving identity-sharpening feedback.

Other entrepreneurs responded to identitysharpening feedback by reflecting on "what is core to the idea," thereby reappraising their psychological ownership by way of abstraction. In one particularly illustrative case, a first-time entrepreneur and selfdescribed "creative" explained how the initial idea had served as a source of excitement for him, stating:
You gotta be crazy to become an entrepreneur, so I think it was actually kind of important that I got wrapped up in our original idea, because, without that excitement, there's no way I would be doing this! (F9)

Subsequently, he described a feedback exchange that led him to reconsider his idea and its importance, ultimately abstracting out to the "bigger problem":

So, essentially, he told us that he couldn't see what was new about our idea ... And, the more we discussed it as a team, the more I was convinced we needed to change, but it was hard to let go. Which is kind of strange, now that I'm talking about it. But that's when we started thinking, "Y'know that, really, what we care about is the bigger problem we're trying to solve. That's why we're doing this." (F9)

Finally, a third group of entrepreneurs viewed the creative revision process metaphorically, using terms like the "game" or "sport" of entrepreneurship (F4; F50; F23). Framing the process in this way enabled them to embrace the philosophy espoused by many of the feedback providers-that attachment to one's ideas is an obstacle to the creative revision process. Consequently, they relinquished any previous psychological ownership of their ideas. For instance, one entrepreneur who had worked in the music industry but was attempting to launch a company in the health care sector decided to sit down with several of his peers within the incubator to discuss the identitysharpening feedback he had received the previous day. At the end of the conversation, he described how his relationship to his ideas had evolved:

I can see why people get disheartened early on in this process and quit. I mean you start out and the idea feels magical, and then you expose it to light and the magic fades. And that's certainly happened with me ... I need to start looking at these ideas as hypotheses that need testing, and then figure out what works and what doesn't. (F19)

Several entrepreneurs were quick to relinquish psychological ownership of their ideas in the face of identity-sharpening feedback, and instead embrace an understanding of their ideas as tentative speculations or evolving components of the overall process.

\section{Idea Work and Identity Work within the Creative Revision Process}

As illustrated in Figure 2, these three different approaches to reappraising one's psychological ownership of a creative idea-reaffirming, abstracting, or relinquishing-allowed for different combinations of 
idea work, which involves updating both the content of a creative idea (i.e., structural idea work) and the presentation of that idea (i.e., rhetorical idea work). Specifically, entrepreneurs reevaluated various assumptions underpinning their ideas, such as value propositions, customers, key activities, marketing channels and relationships, strategic partnerships, resources, cost structures, revenue streams, and strategies related to market entry and growth. However, they approached this process differently in terms of (a) which structural elements were revised, (b) how they were revised, and (c) how the revisions were communicated. I labeled the three observed idea work practices as "defending," "repairing," and "re-engineering," based on the comprehensiveness of the revision efforts. More comprehensive forms of idea work (e.g., re-engineering) at times also included less comprehensive forms of idea work. As illustrated in Figure 2, these different combinations of idea work encouraged particular identity work practices to clarify the relationships between their selfconcepts and culturally based conceptions of the founder role. ${ }^{2}$ Since idea work introduced varying degrees of divergence between feedback recommendations and actual revisions, this work also potentially introduced discrepancies between the entrepreneurs' self-conceptualizations and external role expectations.

On one hand, the entrepreneurs were exposed to an increasingly espoused depiction of the "scientific founder" role that emphasized opportunity commercialization and exploitation by (a) treating ideas as hypotheses, (b) developing prototypes or "minimum viable products," (c) "getting outside the building" to interact with critics so as to refine the hypotheses, and (d) "pivoting" in response to rejection. The scientific founder role was explicitly championed by all of the resource providers, mentors, and incubator administrators, and further reinforced by circulated literature and artifacts, including The Lean Startup (Ries, 2011), Business Model Generation (Osterwalder \& Pigneur, 2010), and The Four Steps to the Epiphany (Blank, 2003). One investor explained:

If [the entrepreneurs] come in and say, "This is my baby and it's beautiful and by God I'm going to sell it to the world," and if they remain passionate about that tactic, that manifestation, they're probably not an entrepreneur.

\footnotetext{
${ }^{2}$ Although prior research has asserted a priori definitions of the founder role involving expectations associated with commercializing and exploiting opportunities (Cardon et al., 2009), this study reveals multiple competing culturally based conceptions of the founder role that specify how individuals should commercialize and exploit opportunities.
}

On the other hand, entrepreneurs were exposed to an equally prominent, yet competing conceptionthe "visionary founder" role. This latter conception alternatively emphasized commercializing and exploiting opportunities by (a) protecting against the fragility of entrepreneurial genius and passion, (b) convincing skeptics by the force of one's conviction, and (c) persisting in response to misunderstanding or rejection. Although expectations associated with the visionary founder role explicitly contradict those associated with the scientific founder role, entrepreneurs were able to find and cite convenient archetypes-most notably, Steve Jobs and Richard Branson-who succeeded by persisting rather than pivoting when confronted with negative feedback. In direct contrast to the aforementioned investor's sentiments, Richard Branson said: "When you believe in something, the force of your convictions will spark other people's interest and motivate them to help you achieve your goals. This is essential to success" (Clarkson, 2015). This visionary founder role thus discourages entrepreneurs from treating their ideas as hypotheses or pivoting amid rejection.

In response to these competing conceptions of the founder role, entrepreneurs took three different approaches to identity work: (1) transcending, (2) decoupling, and (3) professionalizing. In the following subsections, I draw from the compiled vignettes of the founders in my sample to illustrate how differences in the psychological ownership reappraisal process affected their subsequent idea and identity work.

Defending and transcending. By reaffirming psychological ownership of their ideas in response to feedback, some entrepreneurs narrowed the attention and intentions of their revision efforts, treating most changes as personal compromises. Although mentors had suggested significant changes to the ideas, these founders were unwilling to implement them and instead adopted a "defending" approach to idea work as they engaged in efforts to clarify, justify, and expand the assumptions underpinning their creative ideas.

For instance, after observing several feedback exchanges, I sat down with the founder of a social media company (F16) to discuss changes he had implemented and take photos of his evolving business model canvas. The changes illustrate the defending idea work practice. Specifically, this founder continued to add to his business model over time, listing several new marketing channels, critical activities, and key partnerships. This model included the initial customer segment, but specified it as a "subsegment" of a broader intended customer 
group. In addition to these efforts to broaden the original idea, the founder used a spreadsheet to track additional details and supporting arguments. Each row of the spreadsheet represented a section of the business model canvas, and each column offered space to record additional notes and details about his understanding of the idea. When I asked him why he kept such detailed notes about the various components of the business model, the founder responded:

F16: A number of the challenges I faced early on were related to a lack of clarity. While I'm still not concerned what everybody thinks about the idea right now, I think it's important for me to be clear about how I'm going to pull this off. So, I've been using this spreadsheet just as a way to get clear... Any time I hear an argument about why this won't work, I can then respond with these details. And, if it's something I haven't heard before, then I can come back and update the spreadsheet.

INTERVIEWER: Why do you feel it's important to defend your ideas?

F16: For an idea to be good, it has to be new. I believe what I'm trying to do is new, and this means it's confusing to a lot of people. So, I feel like I have to fight sometimes to make people see the value in my ideas.

This quote illustrates how a detailed spreadsheet became a tool that helped this founder clarify and justify various aspects of his business model canvas. Moreover, it illustrates how the individual's psychological ownership of the idea restricted the focus of his creative revision process, contributing to his choice to engage in defending.

Since the scientific founder role frequently prescribed within incubators asserts the value of "pivoting" throughout the creative process, entrepreneurs who engaged in defending practices experienced dissonance between their self-concepts and this prescribed role. Thus, in light of the restricted idea work and their intact psychological ownership, these entrepreneurs rejected the scientific founder role and increased their identification with the visionary founder role. Specifically, they adopted a "transcending" approach to identity work by increasing their identification with roles that portray creative work as non-formulaic (e.g., the visionary founder role). These entrepreneurs rejected roles they viewed as prescribing an overly formulaic approach to commercializing business ideas in favor of roles that encourage wherewithal and persistence, as illustrated in the following two excerpts. In the first excerpt, one founder who had previously responded to feedback by reaffirming his psychological ownership described how he was attempting to move beyond the "reductionist" model of entrepreneurship prescribed by the incubator in favor of one that emphasized "fighting for a better future."

This is why I can't get behind the reductionist mindset of [minimum viable products], pivoting, and the like. When I look at successful founders like Steve Jobs, Bill Gates, [and] Mark Zuckerberg, they envisioned a possible future that others couldn't see or didn't want to see and then they had the wherewithal to make it real. ... As an entrepreneur, this is what defines me-I am envisioning and fighting for a better future. (F22)

Another entrepreneur echoed these thoughts, using the metaphor of the ugly duckling to illustrate how he viewed himself as a "swan" because his idea had greater and longer-term potential:

I'm at a point with my company-it's the ugly duckling story, as far as I can tell, in that I'm not like these other entrepreneurs. Yet I still believe I'm more of a swan. I believe I'm a swan because the potential here is objectively greater than those companies here that are looking for early wins. This idea is going to take time, and a lot of folks here are not interested in ideas that take time. (F25)

These two examples illustrate how defending encouraged entrepreneurs to embrace the visionary founder role as a basis for persisting despite rejection.

Repairing and decoupling. Founders who abstracted the psychological ownership of their ideas increased the degree of flexibility in the creative revision process by allowing for more substantial shifts in the underpinning assumptions as long as the broadly framed value proposition and the associated proposed solutions remained intact. As such, they engaged in both the aforementioned defending practice as well as the more comprehensive idea work practice of "repairing." Specifically, repairing can be understood as idea work that accommodates feedback by questioning the value of specific features of the idea and narrowing the focus of the original assumptions or replacing some of the less essential (i.e., non-core) aspects of the idea (e.g., peripheral mechanics). In one case, a team of founders started with an idea for a mobile health care application that was sweeping in terms of both scope (e.g., the range of services offered within the mobile application) and scale (e.g., mass market, direct to consumer). Initial feedback challenged both the market viability of the idea and the feasibility of 
delivering on such a large-scale endeavor. During team discussions, the founders began to actively consider alternatives to some underpinning assumptions. They juxtaposed ideas on a spreadsheet that they used to inform conversations. In one such conversation, one of the founders admitted, "I think [the feedback providers] have a point. A highvolume, low-margin strategy like this might have some difficulty in such a saturated market” (F14).

Such questioning of the idea was common within the context of the repairing practice. Over the course of three months, the founders made a number of significant changes to the initial idea that illustrate the repairing idea work practice. Most notably, while the value proposition and solution remained the same, they replaced their mass-market, direct-toconsumer approach with a business-to-business marketing strategy focused on transactions with lower volume but a higher margin.

Repairing idea work allowed for some partial overlap between the suggested and actual revisions. The entrepreneurs perceived that they were embracing revision efforts in principled ways that enhanced the feasibility of the idea while remaining consistent with their original intentions. Such idea work enabled these entrepreneurs to demonstrate an appreciation for the scientific founder role without increasing their identification with the role-a form of identity work that I label "decoupling." They viewed the role as a hat that could be worn if and when it was deemed necessary (Mathias \& Williams, 2017). This is similar to the practice described in Kreiner et al.'s (2006) study of identity work among priests, whereby individuals distinguish between the priesthood as something they do versus something they are. During an interview exchange, one founder expressed this as follows:

INTERVIEWER: So, the incubator process has shaped the idea?

F15: Well, it's important to note that, yes, the idea has changed, but we've made these changes in very principled ways ... I've come to realize that I don't really care about the pretense of this start-up culture and what it means to be successful in this environment. So, I recognize that I have to put on the founder hat when I pitch on Thursdays, but that's not what I'm ultimately about or why I'm here.

This interaction thus illustrates how perceptions of principled idea revision can lead to an instrumental approach to accepting and rejecting roles. In other words, when the "founder hat" was necessary to convey legitimacy, entrepreneurs put it on, yet did not closely identify with it.

Other cases across my sample similarly illustrate these practices and how they relate to one another. By abstracting their psychological ownership, founders felt increasingly willing to make "hard" changes that dramatically narrowed core aspects of their ideas. One founder (F1) started with an idea that involved broad ambitions to "connect the creative class to local opportunities, particularly labor opportunities," but subsequently narrowed his value proposition and focused on smaller subsegments of customers and "opportunities" that no longer included connecting individuals with jobs. This founder noted how his efforts to philosophically distinguish between his original idea and his broader vision enabled him to break down and rebuild his idea while decoupling from the founder role he was "playing":

I was caught up originally in an idea-y'know, idea with a small "i"-and people were critiquing that idea from different angles, and rightfully so. But what's important is that I haven't lost sight of our idea with a big "I" ... [You must] distance yourself from that story and have a hard look at it and realize that it's not real. The story itself isn't real; it's a tool. And your identification with that story, the character that you're playing in it also isn't real. I think there are ways of deepening the story and making it more real for more people, constantly breaking it down and rebuilding it. (F1)

Re-engineering and professionalizing. By relinquishing prior psychological ownership of their ideas, entrepreneurs maximized flexibility in subsequent revision processes. Without any strong commitment to prior ideas, these entrepreneurs were able to broaden their attention and intentions and actively incorporate feedback, even in cases in which doing so entailed wholesale replacement of core components of their ideas. As such, they engaged not only in defending and repairing practices, but also in the most comprehensive idea work practice, "re-engineering," defined as fully incorporating feedback and replacing the key assumptions underpinning creative ideas. For example, after receiving identity-sharpening feedback, one founder understood that "it was important to recognize that [he is] not the expert, and so it makes total sense to loosen [his] grip on the idea" (F19). He and his technical cofounder primarily employed the reengineering practice by leveraging connections in the incubator to arrange meetings with a number of 
local business leaders and considering potential gaps in employee health coverage. As a result, the founders decided to revise their ideas to focus on corporate wellness services, scrapping their entire original business model in the process. The founder explained:

Ideas are a dime a dozen. What we do now is that any time one of us has a new suggestion, we immediately document it, and then we start writing down everything that's wrong with that suggestion. I realize this might not be the typical way to do things, but it ensures that only the best suggestions survive. (F19)

Criticizing ideas and replacing core components typify the idea work practice of re-engineering. By shifting from viewing their ideas as ends in and of themselves, and toward viewing them as means for establishing a successful company, the founders perceived unlimited creative discretion as they revised their ideas.

By incorporating all feedback, they not only aligned their ideas with external advice, but also identified with the qualities that characterize the prescribed scientific founder role. I label this identity work practice "professionalizing," given its emphasis on increasing identification with roles that portray creative work as formulaic. ${ }^{3}$ For instance, one founder described what he had found personally meaningful during the process:

F6: At the beginning, I would say that I didn't know what I didn't know, and so at that time I got into this somewhat naively, but the reason I did was because I was really excited about the idea. Pretty quickly, I realized that the idea wasn't going to work, but that's when my faith in the process of customer development started to kick in. So, right now, I think I derive the most meaning through the community and through the struggle of becoming a great entrepreneur...

INTERVIEWER: When you said you "derived meaning from becoming a great entrepreneur," what did you mean?

\footnotetext{
${ }^{3}$ My usage of the "professionalizing" label is consistent with studies in organization theory that have explored how broader cultural beliefs and rules can encourage formulaic practices in specific occupations (e.g., Lounsbury, 2007). Interestingly, although entrepreneurship has not traditionally been considered a profession from a formal academic standpoint, the ubiquity of emergent entrepreneurial standards and institutions that uphold those standards suggests that it is increasingly apt to think of it as such.
}

F6: Yeah, so, I mean basically everything we've been taught here-I've bought in. I think a great entrepreneur is one that can take any idea, break it apart, and revise it until it works ... And that's basically how I see myself now-someone who can build businesses by testing assumptions and figuring out what's generating the most revenue.

\section{How Collective Sensemaking and Prior Experience Shape the Creative Revision Process}

To this point, I have described three different paths through the creative revision process, entailing different forms of psychological ownership reappraisal, idea work, and identity work. But, why did entrepreneurs take different paths through this process? My analysis suggests that entrepreneurs' relative embrace of collective sensemaking and differences in their creative experience play a critical role in shaping the creative revision process.

Collective sensemaking. After receiving identitysharpening feedback, entrepreneurs entered a processing phase, either individually or collectively. In the sample, 29 founders were part of a cofounding team and 26 were residents in an incubator. These different groups were important to the creative revision process, in that they allowed for collective sensemaking about the feedback and about the process of creative revision. Specifically, founders and their peers (e.g., other founders of similar status and with similar social experiences) within the incubators affected the creative revision process by increasing dialogue about the ideas and the feedback. Such dialogue affected entrepreneurs' attention to the feedback (e.g., by causing them to "think twice" about the advice) as well as their intentions, encouraging a pragmatic (e.g., outcome-oriented) rather than idealistic (e.g., values-oriented) and typically defensive response. By the very act of discussing challenging feedback, cofounding teams conferred a certain degree of legitimacy to it that enabled members of the team to reconsider its merits. As team members opened up to one another about questions they had regarding their ideas and exposed opportunities for compromise, founders also became more willing to alter or relinquish their psychological ownership. During an internal group meeting between two cofounders, I observed how the discussion shaped their attention and intentions as they reflected pragmatically on the usefulness of the feedback and the need for revision: 
F15: Okay, we've been going around in circles here for the past hour, but I think the main point is that we need a better investable story and our original idea is too unfocused at this point.

F14: We have to pivot, no question, and, as much as I hate to admit it, I think [the potential investor's] suggestion about focusing on [a narrower understanding of the value proposition] is useful.

F15: And, in some ways, I don't view this as a massive change. I mean, in essence, this is still what we set out to do; it's just kind of a more manageable version of our value proposition.

By definition, collective sensemaking also increased entrepreneurs' exposure to others who were responding to feedback by engaging in idea work and identity work. Such exposure tended to affect the relationship between idea and identity work in two different ways. First, it helped to clarify the scientific and visionary founder roles, thereby compressing the time between idea work and identity work. In other words, these peer-based interactions enabled them to more swiftly understand the perceived requirements associated with each role and thus begin to shift their identification. One entrepreneur, for instance, expressed how his interactions with other entrepreneurs helped refine his understanding of role expectations: "What's interesting is that many of us are really just learning what it means to be an entrepreneur ... So, for me, the best education just has been spending time with other entrepreneurs" (F11). Second, through increased exposure to similar entrepreneurs and their feedback responses, collective sensemaking tended to reinforce the relationship between specific identity work practices and idea work practices. Because entrepreneurs tended to engage in collective sensemaking with peers based on their corresponding identification, their interactions thus encouraged mimetic adoption and validation of similar idea and identity work practices over time.

Breadth of creative work experience. In addition to differences in peer group involvement, I identified differences in the breadth of creative work experience among founders in the sample. While some had highly diversified creative experiences launching companies across industries and creative fields (e.g., one founder had launched companies in the textiles, sports entertainment, and media industries), others had more specialized experience (e.g., another founder launched a company in the industry in which he had specialized for more than 20 years) or rather limited creative work experience. Founders with more diversified prior experience, for instance, tended to be more receptive to identity-sharpening feedback practices, perceived outsiders' creative inputs to have more value, and rarely took idea- or task-based feedback personally. These individuals perceived knowledge as distributed and thus tended to expect challenging feedback, even from those who were less familiar with their ideas. Alternatively, individuals with specialized or limited creative work experience tended to perceive outsiders as challenging their creative authority or domain expertise and thus their self-concepts.

Interview data from two successful founders at similar stages of their careers yet with different levels of creative work experience illustrate this contrast. While the first had launched and run two different prior businesses in different industries and was currently launching his third in yet another industry, the second was launching a new business in the same industry in which he had spent his career. When I asked them to reflect on the critical feedback they had received regarding their ideas, the first replied:

So, I view myself as a boundary spanner, because I have such eclectic experience in both medical devices as well entertainment ... One thing I've had to learn over the course of my career working in very different spaces is that critical feedback of my ideas is valuable, regardless of the source. Different perspectives help me see things I couldn't have possibly seen on my own. I mean, even in cases when the quality of the feedback is sub-par, I still can usually find something useful. (F28)

In contrast, the second responded:

I think there's reason to be wary and skeptical of critical feedback, particularly during the early stages, when I think most ideas end up dying ... The guys in here giving feedback are generalists. I've been working in this field for 20-odd years, so it's really no surprise if they're not tracking with my ideas. (F42)

The breadth of entrepreneurs' prior creative work experience not only conditioned the psychological ownership reappraisal process, but also affected the relationship between idea and identity work. As with increases in collective sensemaking, more extensive and diverse prior experience equipped entrepreneurs with a clearer understanding of the scientific and visionary founder roles, thereby facilitating identity work. Such clarity thus compressed the number of instances of feedback and idea work 
necessary to trigger subsequent identity work. For instance, the first founder quoted above described how his substantial experience gave him greater knowledge of the founder role: "This is just something you pick up along the way through a lot of trial and error ... the knowledge of what it takes to be a successful founder" (F28).

\section{The Effects of Identity Work Practices on Optimal Distinctiveness}

As illustrated, entrepreneurs used identity work practices to reconcile their self-concepts with the founder roles they were exposed to as they moved through the creative revision process. Entrepreneurs who engaged in transcending increased their identification with the visionary founder role, those who engaged in professionalizing increased their identification with the scientific founder role, and those who engaged in decoupling dis-identified from any socially prescribed founder roles. As illustrated by the quotes in prior sections, each of these practices provided the entrepreneurs with a sense of clarity regarding the overlap between their self-concepts and their work. Importantly, however, the different frameworks they used to reposition their selfconcepts affected their ability to achieve a sense of optimal distinctiveness as members of the local entrepreneurial community. "Optimal distinctiveness" is achieved when the psychological needs for assimilation and differentiation are balanced through group affiliation (Brewer, 1991). ${ }^{4}$ Such an outcome is of critical importance to entrepreneurship and the creative revision process, as imbalance can affect material outcomes related to an idea (e.g., funding) and the entrepreneur (e.g., exit from a particular feedback/resourcing community, exit from a venture). In this section, I illustrate the relationship between each of the three identity work practices and their effects on the ability to achieve optimal distinctiveness within a local entrepreneurial community.

Effects of transcending on optimal distinctiveness. Since transcending involves increased identification with the visionary founder role, entrepreneurs who adopted this approach signaled that their ideas were

\footnotetext{
${ }^{4}$ Although it is possible for individuals to achieve optimal distinctiveness by way of multiple group memberships (i.e., assimilating into one, differentiating from another), evidence suggests that balancing assimilation and differentiation within groups increases group identification (Brewer, 1991).
}

unique and should not be subject to the same scrutiny. In other words, they viewed themselves as different from the other founders, and, increasingly, as outsiders to the local entrepreneurial community. As such, they began to frame additional exposure to identity-sharpening feedback as affirming their distinctiveness, thus "fueling the fire" to succeed. One entrepreneur explained:

It's fueling my fire. I want it to succeed that much more just so I can say, "I told you it'd work." And that's really honestly how I operate. So, all these advisors should be telling me "It's a horrible idea, you'll never do it," and then, you know, I'll whip it out in six months. Might speed up the process for me. (F31)

This type of perceived differentiation emboldened entrepreneurs' commitment to their projects, yet led them to begin distancing themselves from feedback providers, whom they perceived as misinformed or misunderstanding. For instance, a number of these entrepreneurs stopped going to social events attended by their peers and feedback providers. Whether self-induced or community induced, such isolation became deleterious to the entrepreneurs' ability to attract resources. Without feedback, it was also difficult for the entrepreneurs to obtain clarity on how to proceed. One entrepreneur from the sciences expressed this during his exit interview with me:

I've never really seen the point of trying to get feedback from people that don't or can't or won't understand what you're trying to do. But, yeah, it's difficult going at this alone without input-I get that. I've been thinking about applying to some educational programs that might get me into circles of other like-minded scientists, and then maybe I'd have some skills that I could bring back to this idea one day. (F25)

These quotes illustrate how transcending enhanced entrepreneurs' sense of differentiation yet impeded their assimilation, leading them to seek membership in other expert communities that might provide a stronger fit.

Effects of professionalizing on optimal distinctiveness. Since professionalizing involves increased identification with the community-prescribed scientific founder role, the approach prioritizes assimilation over differentiation with respect to the entrepreneurial community. For instance, halfway through his residency in one of the incubators, one entrepreneur explained:

I honestly can't imagine a better environment for learning the science behind entrepreneurship. I've 
learned so much from [the individuals in charge] and from all of the other teams. There's a real sense of camaraderie. I mean, I know at the end of the day we're sort of competing for investment, but it's like any sport, where you're cheering for your own team to win, but you also just want the sport to thrive. And y'know, like, in some ways I'm just excited about becoming a better overall competitor. (F4)

This quote illustrates how professionalizing led founders to frame entrepreneurship as a game, wherein winning and losing was less about realizing the potential of a creative idea and more about garnering investment, landing the first customer, or becoming a better professional/entrepreneur in general.

While this practice offered the entrepreneurs a means of strengthening their affiliations with the local entrepreneurial community, it diminished the strength of their sense of distinctiveness. As such, the practice rendered the entrepreneurs more susceptible to new entrepreneurial or career opportunities that might better affirm their unique creativity. For instance, during an exit interview, one entrepreneur who had engaged in professionalizing admitted:

As a matter of fact, I've gone into this whole business venture with the intention of writing a check myself to this business and I'm not ready to do that yet. And I wanted to get to that point. And quite frankly I don't know that I could ask anybody to write a check until I'm ready to do it myself ... Honestly, I feel like I need to find an idea that more closely aligns with the things I care about. (F7)

As this quote illustrates, entrepreneurs who engaged in professionalizing were susceptible to new opportunities and ideas that were better aligned with their unique interests.

Effects of decoupling on optimal distinctiveness. Although decoupling involves dis-identification with the different founder roles, the entrepreneurs who adopted this approach still perceived a strong degree of assimilation. They embraced professional obligations associated with commercialization (e.g., "to wear the [scientific] founder hat" or "play the part") when it was deemed useful for stewarding an idea's success. For instance, during an exit interview, an entrepreneur reflected on her next steps:

Look, there's a part of me that realizes that this pitching and fundraising process is totally a game, for sure. But it's an important game for me to play at times in order to get the right types of access and support that I need to make this a reality. So, for me, I'm completely happy to engage and play the part for as long as I think it will enhance the credibility of what we're doing. (F26)

Simultaneously, decoupling affirmed their perceived differentiation, as their self-concepts remained anchored to their psychological ownership of a particular creative vision for change, albeit a much broader and more abstract vision than originally articulated. In this way, psychological ownership of a creative idea affirmed their sense of uniqueness. One entrepreneur explained this during his final interview with me:

There's a problem staring me in the face every morning when I wake up, and there's a belief that something like what we're doing needs to happen and is going to happen ... My idea from the start was to do something fundamentally different with [this business], so I'm super proud that we've been able to hang onto this vision. (F9)

Thus, decoupling provided entrepreneurs with a sense of optimal distinctiveness - the ability to both fit in with and stand out from the local start-up community.

\section{DISCUSSION}

\section{Toward an Identity-Based Theory of Creative Revision}

My review of the existing literature suggests that the feedback process shapes prototype development by directing creative workers' attention and influencing their intentions. The findings from this study contribute to and extend this understanding of the feedback process by highlighting how such attention and intentions are further shaped by creative workers' self-concepts. The identity-based model of creative revision surfaced in this study (see Figure 2) specifically emphasizes entrepreneurs' psychological ownership as a linchpin in this process. Individuals' psychological ownership of their ideas corresponded with their initial identification as inventors more broadly, compelling efforts to pursue those ideas despite associated challenges. Conversely, to the extent that it was maintained, such psychological ownership restricted the revision of ideas, particularly after the receipt of identitysharpening feedback.

Despite this restriction, the findings illustrate that many of the ideas did change, and some quite drastically. Individuals who engaged in collective sensemaking found merit in relinquishing at least 
some of the psychological ownership of ideas, and this effect was accentuated for those with more eclectic prior creative work experience. The entrepreneurs who reaffirmed their psychological ownership thus were more highly restricted in their idea and identity work than those who abstracted or relinquished such ownership. These relationships operated through the mechanism of entrepreneurs' constrained attention and intentions, which led entrepreneurs to overlook or dismiss much of the advice and criticism they received.

Divergence between the proposed and actual ideabased revisions introduced varying levels of misalignment between individuals' self-concepts and the scientific founder role prescribed by the local entrepreneurial community. Although identity work practices resolved ambiguity in entrepreneurs' self-concepts, they differed in their effects on the entrepreneurs' abilities to achieve a sense of optimal distinctiveness within the local entrepreneurial community. Entrepreneurs who identified with the visionary founder role prioritized differentiation over assimilation, which led them to search for other communities that might support their ideas. Conversely, entrepreneurs who identified most closely with the scientific founder role prioritized assimilation over differentiation, rendering them susceptible to other ideas and opportunities that might better align with their unique interests. Only entrepreneurs who separated their self-concepts from the diverging cultural conceptions of the founder role were able to balance commitments to both their creative projects and the professional community.

Taken together, this emergent model and theory offer several counterintuitive implications that challenge and extend existing scholarship. I elaborate on each of these contributions below.

\section{Expanding Our Understanding of the Creative Revision Process}

The existing literature on creative work both inside and outside the context of entrepreneurship is concerned with the implications of feedback as multiple parties critique and develop new creative products (Hargadon \& Bechky, 2006; Hargadon \& Sutton, 1997; Shah \& Tripsas, 2007; Sonenshein, 2013; Uzzi \& Spiro, 2005). This research is focused on outlining the practices and social networks that underpin collective acts of creativity (Harrison \& Rouse, 2015; Perry-Smith \& Mannucci, 2015), attending less to the identity-based dynamics that might affect creative revision. The process model surfaced in this paper highlights that, although the revision of ideas in response to external feedback is a critical step in the creative process, such work is constrained by creative workers' psychological ownership of their ideas, often requiring subsequent efforts to reposition their self-concepts. This insight offers important implications for research.

The notion that creative workers' psychological ownership of their ideas conditions their subsequent idea and identity work increases our understanding of the challenges associated with the creative revision process. A review of the literature reveals that, thus far, scholars typically have examined these topics independently, assuming that idea work is focused on overcoming informational constraints (Harrison \& Rouse, 2015) while identity work involves forming or reforming one's self-concept within the context of demanding or changing roles (Kreiner et al., 2006). My findings reveal that identity-sharpening feedback practices not only highlight deficiencies in the proposed ideas, but also challenge individuals' self-concepts. As individuals respond to such feedback, they must consider adjusting not only their ideas, but also the extent to which their self-concepts are rooted in those ideas.

My findings also provide insight into the tension posed by the first epigraph of this paper, whereby entrepreneurs are expected to be determined and stubborn yet flexible and adaptive. The findings suggest that these ostensibly competing demands correspond with a higher-order demand-the need to achieve or regain a sense of optimal distinctiveness within the entrepreneurial community (Brewer, 1991). Entrepreneurs who refuse to accommodate external demands retain their distinctiveness, but run the risk of being viewed as stubborn, whereas those who accommodate all demands assimilate well, but run the risk of "holding nothing sacred." Surprisingly, among the three identity work practices employed by entrepreneurs during the creative revision process, only one of these practicesdecoupling-enables entrepreneurs to achieve a sense of optimal distinctiveness. Entrepreneurs who engage in decoupling dis-identify with the socially prescribed founder role altogether, such that their self-concepts remain anchored to the broad creative problems they seek to address, while also allowing the underpinning assumptions to change shape in accordance with external feedback.

While my findings largely focus on the importance of optimal distinctiveness within the context of two particular start-up incubators, the importance of this outcome should not be viewed as artifactual or 
idiosyncratic to this setting. Since many entrepreneurs and creative workers encounter liabilities of newness as they seek to introduce novel and useful solutions to the world, they are exceptionally dependent on group memberships that might alleviate those liabilities (Amezcua, Grimes, Bradley, \& Wiklund, 2013). At the same time, because those entrepreneurs and creative workers often have a disproportionate desire for autonomy, such group memberships remain precarious unless those individuals can achieve a sense of optimal distinctiveness (Elsbach \& Flynn, 2013). Consequently, perceiving limited opportunities for such optimal distinction within those critical groups can threaten creative workers' identification with such groups and result in important, material implications for entrepreneurs and their ideas. While my findings are suggestive in highlighting potential material consequences (e.g., departing the incubator, joining a new start-up) for both the idea and the entrepreneur when optimal distinctiveness is lacking, it is less clear how the presence of optimal distinctiveness within these feedback communities might alternatively affect long-term success. Future research on creativity, innovation, and entrepreneurship should explore how optimal distinctiveness within groups and across groups contributes to important long-term outcomes such as persistence and audience evaluations over time.

\section{Bridging Research on Psychological Ownership and Founder Identities}

More specific to existing research on entrepreneurship, the findings from this study, which clarify that entrepreneurs' psychological ownership of ideas serves as an initial identity anchor within the commercialization process, contribute to and extend recent studies of founder identities (Cardon et al., 2009; Fauchart \& Gruber, 2011; Powell \& Baker, 2014; Shepherd \& Haynie, 2009). This growing body of work has revealed that entrepreneurs derive their self-concepts from broad social groups or categories (e.g., environmentalists) as well as from the specific roles that characterize the commercialization process (e.g., inventor, founder). My research suggests, however, that, although these prior studies provide a basis for understanding commitments to a set of behaviors more generally (e.g., becoming an activist, launching or joining a start-up), they cannot explain entrepreneurs' commitments to transforming ideas into reality. The findings from this study address this gap, highlighting specifically how psychological ownership of particular creative ideas informs decisions to pursue and persist with particular entrepreneurial projects.

By bridging the literatures on psychological ownership and founder identities, this study also provides insight into how and why those identities shift over time. While prior research has suggested that entrepreneurs tend to consistently identify with particular roles (i.e., inventor, founder, developer), thereby affecting their passion for specific activities over time (Cardon et al., 2009), my findings alternatively suggest that the salience of a particular role likely evolves over time by way of identity work (see also Mathias \& Williams, 2017). For instance, entrepreneurs in this study with strong psychological ownership of their ideas initially embraced the inventor role, but, as they received feedback on their ideas, the role expectations associated with commercializing and exploiting opportunities (i.e., founder role) became more salient.

Third, in bridging these two literatures, this study deepens scholarly understandings of psychological ownership. In prior research, scholars have focused largely on how psychological ownership emerges because it increases self-efficacy, affirms one's identity, and serves as a target of personal investment (Pierce et al., 2003). Although scholars have shown that feedback can trigger a sense of loss among individuals who maintain psychological ownership over their ideas (Baer \& Brown, 2012), it has been assumed that those individuals retain their high levels of psychological ownership after receiving such feedback, causing them to resist suggestions for change. By taking a process perspective and examining feedback and psychological ownership over time, I have challenged and extended this literature. Specifically, by introducing the concept of psychological ownership reappraisal, the findings specify several different ways in which psychological ownership evolves, while exposing the conditions under which such evolution occurs. Thus, this study offers insight into the importance of reappraisal in constraining and enabling the creative revision process as well as the embracement of particular creative roles.

\section{Founder Roles as Dynamic and Equivocal}

Although studies of identity work make it clear that identities may change over time, scholars typically have assumed that the social roles and social categories from which entrepreneurs derive those identities are likely to remain stable. Hence, in several early studies, researchers focused on surfacing 
typologies that define and illustrate the range of possible identities for entrepreneurs to adopt (Cardon et al., 2009; Fauchart \& Gruber, 2011). Specifically, research stemming from social identity theory denoted several founder identities, such as "Darwinian," "missionary," and "communitarian," that helped delineate the types of organizations a particular entrepreneur might choose to form (Fauchart \& Gruber, 2011). Alternatively, research stemming from identity theory surfaced a set of roles such as "founder," "inventor," and "developer" that have been used to empirically examine entrepreneurs' passion at various stages of organizational formation (Cardon, Gregoire, Stevens, \& Patel, 2013; Cardon \& Kirk, 2015; Cardon et al., 2009). While these typologies are useful for explaining variance in the entrepreneurial process, my findings suggest that the categories and roles from which entrepreneurs construct their identities are subject to various cultural reference points in practice. As such, because the founder role is culturally situated, it may be ascribed different attributes at different points in time by different social communities. In my setting, this resulted in two alternative cultural conceptions of the founder role that vied for the entrepreneurs' allegiance (i.e., visionary and scientific).

In the future, researchers should thus move beyond decontextualized typologies that define the range and parameters of possible roles and social categories from which entrepreneurs can derive their identities. Examining how these roles and categories are in flux would further enhance our understanding of the complex and lived reality of entrepreneurs as they move through the challenging process of commercializing their ideas. Moreover, my findings highlight that, in the midst of such role equivocality, entrepreneurs struggle to achieve optimal distinctiveness. Thus, another key and important theoretical implication for identity scholarship is that changing and equivocal role identities may produce paradoxical prescriptions (e.g., be stubborn yet flexible) that can create confusion (if not crisis) as entrepreneurs navigate social demands.

\section{Feedback on Feedback: The Importance of Collective Sensemaking}

In prior studies on social identity, researchers have asserted that members of peer groups often exhibit high solidarity; occasionally, in-group solidarity leads to bias that can challenge interactions with outsiders (Hewstone, Rubin, \& Willis, 2002; Tajfel \& Turner, 1979). Given these arguments, I was surprised to find that the founders in my study who were most likely to incorporate extensive and dramatic change in response to external feedback were those who were also most extensively embedded within peer groups and conversant with their peers. For instance, among the 26 incubator residents in my sample, 17 had cofounders. In all 17 cases, the entrepreneurs engaged in more extensive forms of idea and identity work, suggesting a striking reinforcing effect between incubator peers and cofounders in encouraging entrepreneurs to relinquish at least some psychological ownership of their ideas. In other words, collective sensemaking efforts with those in similar social positions enhanced rather than detracted from a willingness to accommodate external demands.

The findings suggest that these peer group conversations created a context in which entrepreneurs could "depersonalize" external feedback, and thereby more seriously consider the assumptions and evidence offered therein. Through collective sensemaking, entrepreneurs were able to view idea-based feedback as a standard part of the creative revision process rather than as personal criticism. This finding introduces an opportunity for researchers to more systematically examine the conditions that might affect this relationship between collective sensemaking and effective creative revision. For instance, the characteristics of the peer group (e.g., size, diversity, team identity) or specific peer group members (e.g., social identities, psychological ownership) might further affect or condition this relationship. Less diversity, for example, may lead to a pronounced "echo chamber effect" in which initial attention and intentions are reinforced rather than broadened. In the future, researchers also might consider collective identities within particular teams and groups, how those collective identities are negotiated during creative revision, and how they affect individuals' identities.

\section{Limitations and Additional Opportunities for Future Research}

The insights generated by this study for understanding the creative revision process are grounded in my choice to focus on the idea stage of entrepreneurship (i.e., the pre-revenue, pre-customer, pre-funding stage). This choice enabled me to isolate identity and idea work prior to the introduction of additional accountabilities and dependencies (e.g., employees, investors) that are likely to complicate the theoretical model yet are important components of the entrepreneurial process and entrepreneurial action. In the future, scholars might look for opportunities to build on 
the identity-based model of creative revision surfaced in this study by examining how increased accountability and resource dependencies in later stages of the entrepreneurial process condition the identity and idea work that ensues. Similarly, researchers might seek to understand the long-term effects of such identity and idea work during the idea stage. How, for instance, might particular idea and identity work practices imprint onto the organizational culture of consequent organizations (Baron, Hannan, \& Burton, 1999) or contribute to the resilience and success of the founders (Cardon \& Kirk, 2015; Rouse, 2016)?

Insights from this study also are grounded in the particular founders I chose to study, who operated in different contexts: some resided within incubators, others occasionally visited these incubators, and others maintained no relationship with the incubators. I believe that these contextual differences improve the study, in that they help substantiate the generalizability of the findings to some extent. That said, all of the founders in this study were highly involved in generating their ideas, and thus were prone to perceive those ideas as both highly novel and highly personal. Also, all were involved in attempts to raise capital, which meant they were exposed to potential status, power, and goal differences that exacerbated the perceived need to change. As such, these individuals were embedded within "multiplex" role relationships, a factor that might accentuate the identity implications for feedback. These individuals were particularly appropriate for observing entrepreneurs' identity-based relationships with their ideas and their responses to challenging feedback; yet, it is important to note the opportunity for future research that would involve expanding the sample. While most entrepreneurs pursue financing, only a relative minority are involved in the type of equity-based financing efforts pursued by those in my sample. In the future, researchers could attempt to test the practices, conditions, and theoretical relationships surfaced in this study with different types of founders (e.g., "necessity" entrepreneurs, franchise operators, founders recruited later in the process for their expertise who have little idea-based involvement) and different types of creative workers (e.g., artists, designers, scholars). If, however, creative workers in a variety of different contexts are frequently exposed to challenging feedback in their efforts to turn their ideas into reality-which seems to be the case-then this study has surfaced an important theoretical gap and the foundations of an identity-based theory of creative revision to help address it.

\section{REFERENCES}

Amezcua, A. S., Grimes, M. G., Bradley, S. W., \& Wiklund, J. 2013. Organizational sponsorship and founding environments: A contingency view on the survival of business-incubated firms, 1994-2007. Academy of Management Journal, 56: 1628-1654.

Anderson, N., Potočnik, K., \& Zhou, J. 2014. Innovation and creativity in organizations: A state-of-the-science review, prospective commentary, and guiding framework. Journal of Management, 40: 1297-1333.

Baer, M. 2012. Putting creativity to work: The implementation of creative ideas in organizations. Academy of Management Journal, 55: 1102-1119.

Baer, M., \& Brown, G. 2012. Blind in one eye: How psychological ownership of ideas affects the types of suggestions people adopt. Organizational Behavior and Human Decision Processes, 118: 60-71.

Bammens, Y., \& Collewaert, V. 2014. Trust between entrepreneurs and angel investors: Exploring positive and negative implications for venture performance assessments. Journal of Management, 40: 1980-2008.

Baron, J. N., Hannan, M. T., \& Burton, M. D. 1999. Building the iron cage: Determinants of managerial intensity in the early years of organizations. American Sociological Review, 64: 527-547.

Beech, N., Gilmore, C., Cochrane, E., \& Greig, G. 2012. Identity work as a response to tensions: A re-narration in opera rehearsals. Scandinavian Journal of Management, 28: 39-47.

Belk, R. W. 1988. Possessions and the extended self. The Journal of Consumer Research, 15: 139-168.

Blank, S. 2003. The Four Steps to the Epiphany: Successful Strategies for Products That Win. K \& S Ranch.

Brewer, M. B. 1991. The social self: On being the same and different at the same time. Personality and Social Psychology Bulletin, 17: 475-482.

Brown, G., \& Baer, M. 2015. Protecting the turf: The effect of territorial marking on others' creativity. The Journal of Applied Psychology, 100: 1785-1797.

Brown, G., Lawrence, T. B., \& Robinson, S. L. 2005. Territoriality in organizations. Academy of Management Review, 30: 577-594.

Burke, P. J. 1991. Identity processes and social stress. American Sociological Review, 56: 836-849.

Burke, P. J., \& Reitzes, D. C. 1981. The link between identity and role performance. Social Psychology Quarterly, 44: 83-92.

Burke, P. J., \& Reitzes, D. C. 1991. An identity theory approach to commitment. Social Psychology Quarterly, 54: 239-251. 
Cardon, M. S., Gregoire, D. A., Stevens, C. E., \& Patel, P. C. 2013. Measuring entrepreneurial passion: Conceptual foundations and scale validation. Journal of Business Venturing, 28: 373-396.

Cardon, M. S., \& Kirk, C. P. 2015. Entrepreneurial passion as mediator of the self-efficacy to persistence relationship. Entrepreneurship Theory and Practice, 39: 1027-1050.

Cardon, M. S., Wincent, J., Singh, J., \& Drnovsek, M. 2009. The nature and experience of entrepreneurial passion. Academy of Management Review, 34: 511-532.

Carlsen, A., Clegg, S., \& Gjersvik, R. 2012. Idea work: Lessons of the extraordinary in everyday creativity. Oslo, Norway: Cappelen Damm Akademisk.

Clarkson, N. 2015, March 25. Richard Branson: The importance of passion in business. Virgin. Retrieved from https://www.virgin.com/entrepreneur/richardbranson-the-importance-of-passion-in-business.

Corley, K. G., \& Gioia, D. A. 2004. Identity ambiguity and change in the wake of a corporate spin-off. Administrative Science Quarterly, 49: 173-208.

Crilly, N. 2017. "Fixation" and "the pivot": Balancing persistence with flexibility in design and entrepreneurship. International Journal of Design Creativity and Innovation, 6: 1-14.

Davies, R., \& Talbot, R. J. 1987. Experiencing ideas: Identity, insight and the imago. Design Studies, 8(1): 17-25.

Denis, J.-L., Dompierre, G., Langley, A., \& Rouleau, L. 2011. Escalating indecision: Between reification and strategic ambiguity. Organization Science, 22: 225-244.

Denzin, N. K., \& Lincoln, Y. S. 1994. Handbook of qualitative research. Thousand Oaks, CA: SAGE.

Eisenhardt, K. M. 1989. Building theories from case study research. Academy of Management Review, 14: 532550.

Eisenhardt, K. M., \& Graebner, M. E. 2007. Theory building from cases: Opportunities and challenges. Academy of Management Journal, 50: 25-32.

Elsbach, K. D. 2009. Identity affirmation through "signature style": A study of toy car designers. Human Relations, 62: 1041-1072.

Elsbach, K. D., \& Flynn, F. J. 2013. Creative collaboration and the self-concept: A study of toy designers. Journal of Management Studies, 50: 515-544.

Elsbach, K. D., \& Kramer, R. M. 2003. Assessing creativity in Hollywood pitch meetings: Evidence for a dualprocess model of creativity judgments. Academy of Management Journal, 46: 283-301.

Fauchart, E., \& Gruber, M. 2011. Darwinians, communitarians, and missionaries: The role of founder identity in entrepreneurship. Academy of Management Journal, 54: 935-957.

Fendt, J., \& Sachs, W. 2008. Grounded theory method in management research. Organizational Research Methods, 11: 430-455.

Ferriss, T. 2015. Alexis Ohanian on Y Combinator, getting punched, and picking winners. The Tim Ferriss Show, episode 36 [Audio podcast]. Retrieved from https:// soundcloud.com/tim-ferriss/alexis-ohanian.

Gioia, D. A., Corley, K. G., \& Hamilton, A. L. 2013. Seeking qualitative rigor in inductive research notes on the Gioia methodology. Organizational Research Methods, 16: $15-31$.

Hargadon, A. B., \& Bechky, B. A. 2006. When collections of creatives become creative collectives: A field study of problem solving at work. Organization Science, 17: 484-500.

Hargadon, A. B., \& Sutton, R. I. 1997. Technology brokering and innovation in a product development firm. Administrative Science Quarterly, 42: 716-749.

Harrison, S. H., \& Rouse, E. D. 2015. An inductive study of feedback interactions over the course of creative projects. Academy of Management Journal, 58: 375-404.

Hewstone, M., Rubin, M., \& Willis, H. 2002. Intergroup bias. Annual Review of Psychology, 53: 575-604.

Koerner, M. M. 2014. Courage as identity work: Accounts of workplace courage. Academy of Management Journal, 57: 63-93.

Kreiner, G. E., Hollensbe, E. C., \& Sheep, M. L. 2006. Where is the "me" among the "we"? Identity work and the search for optimal balance. Academy of Management Journal, 49: 1031-1057.

Langley, A. 1999. Strategies for theorizing from process data. Academy of Management Review, 24: 691-710.

Locke, K. 2001. Grounded theory in management research. Thousand Oaks, CA: SAGE.

Lounsbury, M. 2007. A tale of two cities: Competing logics and practice variation in the professionalizing of mutual funds. Academy of Management Journal, 50: 289-307.

Lounsbury, M., \& Glynn, M. A. 2001. Cultural entrepreneurship: Stories, legitimacy, and the acquisition of resources. Strategic Management Journal, 22: 545-564.

Mathias, B. D., \& Williams, D. W. 2017. Giving up the hats? Entrepreneurs' role transitions and venture growth. Journal of Business Venturing, 33: 261-277.

Osterwalder, A., \& Pigneur, Y. 2010. Business model generation: A handbook for visionaries, game changers, and challengers. Hoboken, NJ: Wiley.

Ozgen, E., \& Baron, R. A. 2007. Social sources of information in opportunity recognition: Effects of 
mentors, industry networks, and professional forums. Journal of Business Venturing, 22: 174-192.

Patton, M. Q. 2002. Qualitative research and evaluation methods, 3rd ed. Thousand Oaks, CA: SAGE.

Perry-Smith, J. E. 2006. Social yet creative: The role of social relationships in facilitating individual creativity. Academy of Management Journal, 49: 85-101.

Perry-Smith, J. E., \& Coff, R. W. 2011. In the mood for entrepreneurial creativity? How optimal group affect differs for generating and selecting ideas for new ventures. Strategic Entrepreneurship Journal, 5: 247-268.

Perry-Smith, J. E., \& Mannucci, P. V. 2015. From creativity to innovation: The social network drivers of the four phases of the idea journey. Academy of Management Review, 42: 53-79.

Perry-Smith, J. E., \& Shalley, C. E. 2003. The social side of creativity: A static and dynamic social network perspective. Academy of Management Review, 28: 89-106.

Petriglieri, J. L. 2011. Under threat: Responses to the consequences of threats to individuals' identities. Academy of Management Review, 36: 641-662.

Pierce, J. L., Kostova, T., \& Dirks, K. T. 2001. Toward a theory of psychological ownership in organizations. Academy of Management Review, 26: 298-310.

Pierce, J. L., Kostova, T., \& Dirks, K. T. 2003. The state of psychological ownership: Integrating and extending a century of research. Review of General Psychology, 7: 84-107.

Powell, E. E., \& Baker, T. 2014. It's what you make of it: Founder identity and enacting strategic responses to adversity. Academy of Management Journal, 57: 1406-1433.

Pratt, M. G., Rockmann, K. W., \& Kaufmann, J. B. 2006. Constructing professional identity: The role of work and identity learning cycles in the customization of identity among medical residents. Academy of Management Journal, 49: 235-262.

Ries, E. 2011. The lean startup: How today's entrepreneurs use continuous innovation to create radically successful businesses. New York, NY: Crown Business.

Rouse, E. 2013. Kill your darlings? Experiencing, maintaining, and changing psychological ownership in creative work (Doctoral dissertation, Boston College). Retrieved from https://dlib.bc.edu/islandora/object/ bc-ir:101452.

Rouse, E. D. 2016. Beginning's end: How founders psychologically disengage from their organizations. Academy of Management Journal, 59: 1605-1629.

Shah, S. K., \& Tripsas, M. 2007. The accidental entrepreneur: The emergent and collective process of user entrepreneurship. Strategic Entrepreneurship Journal, 1: 123-140.
Shepherd, D., \& Haynie, J. M. 2009. Birds of a feather don't always flock together: Identity management in entrepreneurship. Journal of Business Venturing, 24: 316337.

Sonenshein, S. 2013. How organizations foster the creative use of resources. Academy of Management Journal, 57: 814-848.

Stevens, C. K., \& Kristof, A. L. 1995. Making the right impression: A field study of applicant impression management during job interviews. The Journal of Applied Psychology, 80: 587-606.

Strauss, A. L., \& Corbin, J. M. 1990. Basics of qualitative research: Grounded theory procedures and techniques. Newbury Park, CA: SAGE.

Stryker, S., \& Burke, P. J. 2000. The past, present, and future of an identity theory. Social Psychology Quarterly, 63: 284-297.

Stryker, S., \& Serpe, R. T. 1982. Commitment, identity salience, and role behavior: Theory and research example. In W. Ickes \& E. S. Knowles (Eds.), Personality, roles, and social behavior: 199-218. New York, NY: Springer.

Sutton, R. I., \& Hargadon, A. 1996. Brainstorming groups in context: Effectiveness in a product design firm. Administrative Science Quarterly, 41: 685-718.

Tajfel, H., \& Turner, J. C., 1979. An integrative theory of intergroup conflict. In W. G. Austin \& S. Worchel, The social psychology of intergroup relations: $33-47$. Monterey, CA: Brooks Cole.

Turner, J. C., Hogg, M. A., Oakes, P. J., Reicher, S. D., \& Wetherell, M. S. 1987. Rediscovering the social group: A self-categorization theory. Cambridge, MA, US: Basil Blackwell.

Uzzi, B., \& Spiro, J. 2005. Collaboration and creativity: The small world problem. American Journal of Sociology, 111: 447-504.

Van Maanen, J. 1979. The fact of fiction in organizational ethnography. Administrative Science Quarterly, 24: 539-550.

Yin, R. K. 2009. Case study research: Design and methods. Los Angeles, CA: SAGE.

\section{$M$}

Matthew G. Grimes (m.grimes@jbs.cam.ac.uk) is a reader in entrepreneurship and organization at the University of Cambridge's Judge School of Business. His current research focuses on the challenges of idea-stage entrepreneurship and social innovation.

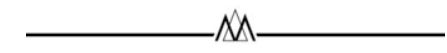


Copyright of Academy of Management Journal is the property of Academy of Management and its content may not be copied or emailed to multiple sites or posted to a listserv without the copyright holder's express written permission. However, users may print, download, or email articles for individual use. 